\title{
1 Viral mimicry of p65/RelA transactivation domain to inhibit NF-kB activation
}

2

3 Jonas D. Albarnaz ${ }^{1 *}$, Hongwei Ren ${ }^{1 \dagger}$, Alice A. Torres ${ }^{1}$, Evgeniya V. Shmeleva ${ }^{1 \ddagger}$, Carlos A.

4 Melo $^{2}$, Andrew J. Bannister ${ }^{2}$, Geoffrey L. Smith ${ }^{1 *}$

5 'Department of Pathology, University of Cambridge, Cambridge CB2 1QP, UK

$6{ }^{2}$ The Gurdon Institute, University of Cambridge, Cambridge CB2 1QN, UK

$8 \quad$ *Corresponding authors: gls37@cam.ac.uk (GLS); j0732@cam.ac.uk (JDA)

9

10 'Present address: Department of Immunology and Inflammation, Imperial College

11 London, Hammersmith Campus, Du Cane Road, London W12 ONN, UK

12 †Present address: Department of Obstetrics and Gynaecology, University of Cambridge, Box

13 223, Level 2, The Rosie Hospital, Robinson Way, Cambridge CB2 2SW, UK

15 Running title: Viral inhibition of NF-KB via molecular mimicry

17 Key words: vaccinia virus, NF-kB, molecular mimicry, p65, CBP, BRD4, virulence, immune 18 evasion, poxvirus 


\section{ABSTRACT}

2 The evolutionary arms race between hosts and their viruses drove the evolution of complex 3 immune systems in mammals and sophisticated immune evasion mechanisms by viruses. 4 Mammalian antiviral defences require sensing of virus infection and stimulation of the 5 expression of interferons and cytokines via the activation of $\mathrm{NF}-\mathrm{KB}$ and other immune 6 signalling pathways. Viruses antagonise these host antiviral defences by interfering with 7 immune sensing and signal transduction and blocking the actions of interferons and 8 cytokines. Here we show that a viral protein mimics the transcription activation domain of $9 \mathrm{p65}$, the transcriptionally active subunit of NF- $\mathrm{kB}$. The $\mathrm{C}$ terminus of vaccinia virus (VACV) protein F14 (residues 51-73) activates transcription when fused to a DNA-binding domaincontaining protein and associates with $\mathrm{NF}-\mathrm{\kappa B}$ co-activator $\mathrm{CBP}$, disrupting its interaction with p65. Consequently, F14 diminishes CBP-mediated acetylation of p65 and the downstream recruitment of RNA polymerase II processivity factor BRD4 to the promoter of NF- $\mathrm{KB}$ responsive gene $C X C L 10$, thereby inhibiting the expression and secretion of CXCL10 upon stimulation with TNF- $\alpha$. A VACV strain engineered to lack F14 caused reduced lesions in an intradermal model of infection, showing that F14 contributes to virulence. Our results uncover a mechanism by which viruses disarm the antiviral defences through molecular mimicry of a conserved protein of the host's immune system. 


\section{INTRODUCTION}

Viruses provide constant selective pressure shaping the evolution of the immune systems of multicellular organisms [1-3]. At the cellular level, an array of receptors detect virus-derived molecules, or more broadly pathogen-associated molecular patterns (PAMPs), allowing the recognition of invading viruses and the activation of a gene expression programme that initiates the antiviral response [reviewed by $[4,5]]$. The induced gene products, which include interferons, cytokines and chemokines, are secreted and function as signals to activate more specialised immune cells and attract them to the site of infection, thereby generating inflammation [reviewed by [6-8]]. This coordinated inflammatory response evolved to achieve the control and (or) elimination of the infection, and the establishment of an immunological memory against future infection [reviewed by [4, 9]].

Engagement of pattern recognition receptors (PRRs) by their cognate PAMPs activates multiple transcription factors, including nuclear factor kappa light-chain enhancer of activated $\mathrm{B}$ cells $(\mathrm{NF}-\mathrm{\kappa B})$ [reviewed by [10-12]]. NF- $\kappa \mathrm{B}$ is a homo- or heterodimer of Rel proteins, with the heterodimer of p50 (also known as NF-kB1 or NFKB1) and p65 (also known as RelA or RELA) being the prototypical form of NF- $K B$ [13]. Through an interface formed by the Rel homology domains of the two Rel subunits, NF- $\mathrm{kB}$ recognises and binds to a consensus DNA sequence in the promoter elements and enhancers of target genes [reviewed by [10], [14]]. NF-kB-responsive gene products include inflammatory mediators, such as cytokines, chemokines and cell adhesion molecules, as well as proteins involved in other immune processes, like MHC molecules, growth factors and regulators of apoptosis [15, 16]. Moreover, cytokines, such as interleukin (IL)-1 and tumour necrosis factor (TNF)- $\alpha$, also trigger NF- $\mathrm{KB}$ activation upon engagement of their receptors on the cell surface [reviewed by $[10,11]]$.

In resting conditions, NF- $\mathrm{KB}$ remains latent in the cytoplasm bound to the inhibitor of $\kappa \mathrm{B}$ $(\mathrm{I} \mathrm{B}) \propto$ (also known as NFKBIA) $[17,18]$. Upon activation, the IKB kinase (IKK) complex phosphorylates $I \kappa B \alpha$, triggering its ubiquitylation and subsequent proteasomal degradation, thus releasing NF- $\kappa B$ to accumulate in the nucleus [18] [reviewed by [10, 11]]. In the nucleus, NF- $\mathrm{KB}$ interacts with chromatin remodelling factors, coactivators and general transcription factors to activate the transcription of antiviral and inflammatory genes by RNA polymerase (RNAP) II [14, 19-24]. The specificity and kinetics of NF-kB-dependent gene expression is determined by several factors including dimer composition [25], cooperation with other transcription factors [the cooperation between NF-kB, activator protein (AP)-1 and interferon regulatory factor (IRF) transcription factors to activate interferon (IFN)- $\beta$ transcription in response to virus infection being a classical example [26]], duration of the stimulus [27, 28], cell type [29, 30] and chromatin context on the promoters of target genes $[14,31,32]$. In addition, NF- $\mathrm{B}$ undergoes multiple posttranslational modifications, in the cytoplasm or nucleus, that control its transcriptional activity through interactions with coactivators and basal transcription machinery [reviewed by [13, 33, 34]].

Following the stimulation with PAMPs (e.g. lipopolysaccharide) or inflammatory cytokines (e.g. TNF- $\alpha$ ), two conserved residues in $p 65$ are phosphorylated: $S^{276}$, mainly by protein kinase A (PKA), and Ser ${ }^{536}$ within the transactivation domain (TAD), by the IKK complex [35, 36]. Phosphorylation of either site enhances NF- $\kappa B$ transcriptional activity by promoting the interaction with the coactivators CREB-binding protein (CBP) or its paralogue p300 (also known as CREBBP and EP300, respectively). These coactivators acetylate p65 at Lys ${ }^{310}$ as well as histones on the target gene promoters to allow transcription initiation and elongation to proceed [36-39]. The bromodomain and extraterminal domain (BET) protein BRD4 docks 
1 onto acetylated p65 Lys ${ }^{310}$ via its two bromodomains and subsequently recruits positive 2 transcription elongation factor $b(P-T E F b)$ to drive transcription of inflammatory genes by 3 RNAP II [40]. This latter study highlighted the complexity of the gene expression programme 4 downstream of NF-KB, with subsets of genes differentially expressed depending on the 5 transcriptional regulatory events following NF- $\kappa B$ recruitment to DNA [[40-42]; reviewed by 6 [43]].

7 The confrontations between viruses and hosts leave genetic signatures over their 8 evolutionary histories [3,44]. On one hand, host innate immune factors display strong signs 9 of positive selection to adapt to the pressure posed by viruses [reviewed by [45]]. On the other hand, viruses acquire multiple mechanisms to antagonise host innate immunity, such as mimicking host factors to disrupt their functions in the antiviral response or to subvert them for immune evasion [reviewed by $[45,46]$ ]. Poxviruses have been a paradigm in the study of virus-host interactions [reviewed by [47]]. Their large DNA genomes encode a plethora of proteins that antagonise the host antiviral response. Some poxvirus proteins show structural similarity to host proteins and modulate innate immune signalling during infection [reviewed by [48, 49]].

Vaccinia virus (VACV), the smallpox vaccine and the prototypical poxvirus, utilises molecular mimicry to antagonise the host response to infection [reviewed by [50]]. VACV-encoded soluble receptors of TNF and IL-1 $\beta$ share amino acid similarity with their cellular counterparts and bind to extracellular cytokines to block the engagement of the cognate cellular receptors and thereby the activation of downstream signalling pathways, including NF- $\mathrm{KB}$ [reviewed by [50,51]]. VACV also encodes a family of proteins sharing structural similarity to cellular Bcl-2 proteins despite very limited sequence similarity. Viral Bcl-2-like proteins have evolved to perform a wide range of functions, such as inhibition of NF- $\mathrm{KB}$ activation [reviewed by [52]]. One example is VACV protein A49, which notwithstanding its $\mathrm{Bcl}-2$ fold, also mimics the $I_{\kappa} \mathrm{B} \alpha$ phosphodegron that is recognised by the $\mathrm{E} 3$ ubiquitin ligase $\beta$-TrCP, thereby blocking $I \kappa B \alpha$ ubiquitylation $[53,54]$. Upon NF- $k B$ activation, the IKK complex phosphorylates $A 49$ to create the complete phosphodegron mimic that then engages with $\beta$-TrCP to prevent IKB $\alpha$ ubiquitylation [55].

Previous work from our laboratory predicted that VACV encodes additional inhibitors of NF$\mathrm{KB}$ because a mutant VACV strain (vv811 $\triangle \mathrm{A} 49$ ) lacking the function of all known inhibitors of NF-kB still suppresses NF-kB-dependent gene expression without preventing NF-KB translocation to the nucleus [56]. Here, we mapped this NF-kB inhibitory activity to the open reading frame (ORF) F14L, which is conserved across all orthopoxviruses including the human pathogens variola, monkeypox and cowpox viruses. Using a combination of gene expression and protein-based assays, we show that F14 from VACV inhibits NF- $\mathrm{KB}$ when expressed ectopically or during infection. Furthermore, a VACV strain lacking F14 has reduced virulence in a mouse model. Mechanistically, the F14 C terminus mimics the transactivation domain (TAD) of p65 and outcompetes p65 for binding to the coactivator CBP. As a consequence, F14 reduces p65 acetylation and downstream molecular events required for the activation of a subset of NF-kB-responsive inflammatory genes. 
RESULTS

\section{Vaccinia virus protein $F 14$ is a virulence factor that inhibits $N F-\kappa B$ activation}

The prediction that VACV encodes additional inhibitor(s) of NF-KB that function downstream of p65 translocation into the nucleus [56], prompted a search for nuclear NF-kB inhibitors. VACV strain vv811 $\triangle A 49$ lacks 56 ORFs, but retains the inhibitor(s) [56, 57], and so its encoded proteins were screened by bioinformatics for ones that met the following criteria: (i) early expression, based on previous VACV transcriptome studies [58, 59]; (ii) predicted not to be involved in replication and/or morphogenesis; (iii) being poorly characterised; (iv) presence of putative nuclear localisation signals (NLS) or predicted molecular mass $<40 \mathrm{kDa}$ that would allow diffusion into the nucleus [60]; and (v) the presence of domains indicative of function. The genomic position of the ORF and its conservation among orthopoxviruses were also considered given that VACV immunomodulatory genes are located towards the genome termini and are sometimes less conserved than genes centrally located that have functions in virus replication [61].

This approach yielded a list of seven ORFs, namely F6L, F7L, F14L, A47L, B6R, B11R and $B 12 R$. These ORFs were codon-optimised for expression in human cells, cloned into pcDNA4/TO and tested for inhibition of NF-kB activation in an NF-kB luciferase reporter gene assay. Protein F14 inhibited TNF- $\alpha$ and IL-1 $\beta$-stimulated NF-kB activity in HEK 293T cells in a dose-dependent manner (Figure 1A, B and Figure S1). This inhibitory activity was specific for the NF-kB pathway, because F14 did not affect IFN-a-stimulated Janus kinase $(\mathrm{JAK})$ /signal transducer and activators of transcription (STAT) or phorbol 12-myristate 13acetate (PMA)-stimulated mitogen-activated protein kinase (MAPK)/AP-1 pathways (Figure $1 C, D)$. The inhibitory activity was exerted despite the lower levels of F14 expression when compared to VACV protein B14, a known inhibitor of NF-KB (Figure 1E) [62]. Conversely, VACV protein C6 suppressed type I IFN signalling and B14 upregulated AP-1 activity, as observed previously (Figure 1C, D) [63, 64].

Most VACV immunomodulatory proteins affect virulence in intranasal or intradermal murine models [reviewed by [50,51]]. To evaluate if loss of F14 expression affected virulence, a recombinant VACV lacking F14 was generated, termed $v \Delta F 14$. Intradermal inoculation of the ear pinnae of mice with $v \Delta \mathrm{F} 14$ produced smaller lesions, and reduced virus titres at 7 and 10 d post-infection (p.i.) (Figure 1F, G) compared to wild type virus ( $\mathrm{VF14}$ ) and a revertant strain ( $\mathrm{vF} 14-\mathrm{Rev})$, generated by reinserting $\mathrm{F} 14$ into $\mathrm{v} \Delta \mathrm{F} 14$ at its natural locus (Figure $1 \mathrm{~F}$ ). Attenuation of $\mathrm{v} \Delta \mathrm{F} 14$ in the intradermal mouse model correlated with reduced viral tires in the infected ears 7 and $10 \mathrm{~d}$ p.i., but not $3 \mathrm{~d}$ p.i. (Figure 1G). In contrast, in an intranasal mouse model $v \Delta \mathrm{F} 14$ caused the same extent of body mass loss as wild type and revertant controls (Figure S2). In cell culture, vF14, v $\Delta \mathrm{F} 14$ and $\mathrm{vF} 14-\mathrm{Rev}$ displayed no differences in replication and plaque size (Figure S3). Altogether, these experiments showed that F14 is not essential for virus replication but makes a modest contribution to virulence.

Previous analyses of VACV transcriptome showed that the F14L ORF is transcribed and translated early during infection $[58,59,65]$. This was consistent with an upstream typical early promoter and a transcription termination motif $T_{5} N T$ downstream of the stop codon [66, 67]. To investigate F14 expression during infection, a VACV strain was constructed in which F14 was tagged with a C-terminal TAP tag. The vF14-TAP strain replicated normally (Figure S3) and immunoblotting showed F14 expression from $4 \mathrm{~h}$ p.i. and peaked by $8 \mathrm{~h}$ p.i., matching the accumulation of another early VACV protein C6 (Figure 1H) [68]. F14 levels were notably lower compared to other VACV proteins tested either when expressed ectopically (Figure 1E) or during infection (Figure $1 \mathrm{H}$ ). This might explain why F14 was not 
detected in our recent quantitative proteomic analysis of VACV infection, which detected about $80 \%$ of the predicted VACV proteins [69]. Pharmacological inhibition of virus DNA replication with cytosine arabinoside (AraC) did not affect F14 protein levels, consistent with early expression, whereas late protein D8 was inhibited (Figure $1 \mathrm{H}$ ).

The existence of multiple VACV inhibitors of NF-kB that each contribute to virulence indicates they are not redundant. To test if $\mathrm{F} 14$ affects NF-KB activation in cell culture we deleted F14 from the vv811 $\triangle \mathrm{A} 49$ strain that lacks other known inhibitors of NF-kB [56] and infected an NF-KB firefly luciferase reporter A549 cell line [56]. As shown previously, vv811 $\triangle A 49$ inhibited NF-KB to a reduced extent when compared to the parental vv811 strain (Figure 1I) [56] and deletion of $F 14 L$ reduced NF-KB inhibition further (Figure 1I). Immunoblotting confirmed equal infection with these viruses (Figure 1J). Notably, vv811 $\Delta \mathrm{A} 49 \Delta \mathrm{F} 14$ still suppressed NF-KB activation considerably, which might be explained by: (i) the existence of additional virally-encoded inhibitors that cooperate to inhibit NF- $\kappa B$ in the nucleus, or (ii) the actions of D9 and D10 decapping enzymes to reduce host mRNA [70, 71].

\section{F14 inhibits NF-KB at or downstream of p65}

To dissect how F14 functions, its impact on three hallmarks of NF-kB signalling were studied: namely degradation of $\mathrm{I} \mathrm{KB} \alpha$, phosphorylation of p65 at S536 and p65 nuclear translocation. A HEK 293T-derived cell line that expresses F14 inducibly upon addition of doxycycline, was used to study the degradation of $1 \kappa B \alpha$, and phosphorylation and nuclear translocation of $\mathrm{p} 65$ following stimulation with TNF- $\alpha$. I $\mathrm{kB} \alpha$ degradation was evident 15 min after stimulation and its re-synthesis had started by $30 \mathrm{~min}$, but neither process was influenced by F14 (Figure 2A). F14 also did not affect phosphorylation of p65 at Ser ${ }^{536}$ (Figure $2 \mathrm{~A}$ ) or p65 translocation into the nucleus as measured by immunofluorescence (Figure 2B). In contrast, VACV protein B14 inhibited translocation efficiently as reported [62], and VACV protein $\mathrm{C6}$, an IFN antagonist [63, 68], did not (Figure 2B).

Next, the NF-KB inhibitory activity of F14 was tested by reporter gene assay following pathway activation by p65 overexpression. In contrast to B14, F14 inhibited p65-mediated activation in a dose-dependent manner without affecting p65 levels (Figure $2 \mathrm{C}$ ). Altogether, these results showed that F14 blocks NF-kB in the nucleus at or downstream of p65. F14 thus fits the criteria described previously for the unknown inhibitor of NF-kB encoded by VACV and expressed by vv811 $\Delta$ A49 [56].

\section{F14 orthologues are conserved in orthopoxviruses and mimic the p65 transactivation domain}

Poxvirus immunomodulatory proteins are generally encoded in the variable genome termini, rather than the central part of the genome that encodes proteins for virus replication, share lower sequence identity and show genus-specific distribution [61]. Even among orthopoxviruses, only a few of the immunomodulatory genes are present in all virus species [61]. Nonetheless, Viral Orthologous Clusters [72] and protein BLAST searches found orthologues of VACV F14 in all orthopoxviruses, with $70.7 \%$ to $98.6 \%$ amino acid (aa) identity (Figure $3 \mathrm{~A}$ ). The C-terminal half of $\mathrm{F} 14$ was more conserved and included a predicted coiled-coil region (aa 34-47), the only structural motif predicted via bioinformatic analyses. However, the Phyre2 algorithm [73] predicted the C-terminal aa 55 to 71 to adopt an $\alpha$-helical secondary structure similar to that of aa 534-546 of p65 in complex with the $\mathrm{PH}$ 
1

domain of human general transcription factor Tfb1, or aa 534-550 of p65 in complex with the KIX domain of NF- $\kappa B$ coactivator CBP [74]. The F14 aa similarity was striking, particularly with p65 aa within a $\phi \times x \phi \phi$ motif essential for NF- $\kappa B$ transcription activity $[74,75]$. The $\mathrm{C}$ terminus of p65 harbours its transactivation domain (TAD), which is divided into two subdomains that are transcriptionally independent: $\mathrm{TA}_{1}$ (aa 521 to 551) and $\mathrm{TA}_{2}$ (aa 428 to 521) $[22,76] . \mathrm{TA}_{1}$ contributes at least $85 \%$ of p65 transcriptional activity and interacts directly with CBP $[22,74,76]$. Notably, in F14 the position equivalent to Ser ${ }^{536}$ in p65, which is phosphorylated upon NF-KB activation [35, 39], is occupied by the negatively charged residue $\mathrm{Asp}^{59}$, a phospho-mimetic (Figure $3 \mathrm{~A}$ ).

These observations and the key role of CBP in NF-кB-dependent gene activation [20], prompted the investigation of whether F14 could interact with CBP. Immunoprecipitation (IP) of HA-tagged F14 co-precipitated CBP-FLAG from HEK 293T cells (Figure 3B). Reciprocal IP experiments showed that ectopic CBP co-precipitated F14-HA, but not GFP-HA, with or without prior TNF- $\alpha$ stimulation (Figure $3 \mathrm{C}$ ). These interactions were also seen at endogenous levels in both HEK 293T and HeLa cells infected with vF14-TAP. F14, but not C6, co-precipitated endogenous CBP (Figure 3D).

To test whether the $\mathrm{C}$ terminus of $\mathrm{F} 14$ mediated transactivation via its binding to CBP, F14 aa 51 to 73 were fused to the $C$ terminus of a p65 mutant lacking the $T A_{1}$ subdomain of the $\operatorname{TAD}\left(\Delta T A_{1}\right)$ and the fusion protein was tested in a NF-KB luciferase reporter gene assay. Compared to wildtype p65, the p65 $\Delta \mathrm{TA}_{1}$ mutant was impaired in its transactivating activity, which was restored to wildtype levels upon fusion to $\mathrm{F} 14_{51-73}$ (Figure $3 \mathrm{E}$ ). This result argues strongly that the $\mathrm{C}$ terminus of $\mathrm{F} 14$ mimics the $\mathrm{TA}_{1}$ of $\mathrm{p} 65$ and this mimicry might explain how F14 inhibits NF-KB activation.

\section{F14 outcompetes NF-KB for binding to CBP}

The similarity between the $\mathrm{C}$ termini of $\mathrm{F} 14$ and p65 led us to investigate if the conserved aa contributed to the NF-KB inhibitory activity of F14. Based on the structure of CBP KIX domain in complex with p65 $\mathrm{TA}_{1}$ [74], residues of F14 TAD-like domain corresponding to residues of $p 65$ important for its binding to CBP were mutated. Three sites were altered by site-directed mutagenesis of F14: the dipeptide Asp ${ }^{62 / 63}$, and the following Leu ${ }^{65}$ and $\mathrm{Leu}^{68}$ of the $\phi \times x \phi \phi$ motif. F14 L65A or L68A still inhibited NF-kB efficiently (Figure 4A). In contrast, mutation of $A s p^{62 / 63}$ to either alanine (D62/63A) or lysine (D62/63K) abolished the inhibitory activity (Figure 4A). Protein expression was comparable across the different F14 mutants (Figure $4 \mathrm{~A}$ ). The loss of NF-KB inhibitory activity of D62/63A and D62/63K mutants correlated with their reduced capacity to co-precipitate CBP, whereas L65A and L68A mutants co-precipitated CBP to the same extent as wildtype F14 (Figure 4B). The mutation of the negatively charged $A s p^{62 / 63}$ to positively charged Lys residues was more efficient in disrupting the interaction between F14 and CBP than only abolishing the charge (Figure 4B). Collectively, these results highlight the importance of the negatively charged dipeptide Asp ${ }^{62 / 63}$ within the TAD-like domain for NF-kB inhibition by F14.

Next we tested if F14 could disrupt the interaction of p65 with its coactivator CBP [20]. HEK 293T cells were transfected with vectors expressing p65 and CBP or RIG-I, and VACV proteins F14 or C6. The amount of p65-HA immunoprecipitated by ectopic CBP was reduced by increasing amounts of F14 but not C6 (Figure 5A, B). Quantitative analysis showed equivalent ectopic CBP immunoprecipitation with or without F14 (Figure 5C). Furthermore, the mutation D62/63K diminished the capacity of F14 to disrupt the interaction of CBP and 
p65 (Figure 5D). This observation correlated well with the reduced capacity of the D62/63K mutant to co-precipitate CBP (Figure 4B).

\section{F14 suppresses expression of a subset of NF-KB-responsive genes}

To address the impact of $\mathrm{F} 14$ on the induction of endogenous NF-kB-responsive genes by TNF- $\alpha$, the T-REx-293 cell lines inducibly expressing F14 or C6 were utilised (Figure 6G). NF-kB-responsive genes display different temporal kinetics upon activation, with "early" gene transcripts peaking between 30-60 min after stimulation before declining, whilst "late" gene transcripts accumulate slowly and progressively, peaking $3 \mathrm{~h}$ post stimulation $[15,16]$. In F14-expressing cells, mRNAs of NFKBIA and CXCL8 "early" genes had equivalent induction kinetics compared to C6-expressing cells (Figure 6A, B). The lack of inhibition of F14 on the expression of NFKBIA mRNA is in agreement with the previous finding that the re-synthesis of $\mathrm{I} \mathrm{KB} \alpha$ (NFKBIA protein product) is unaffected by $\mathrm{F} 14$ after its proteasomal degradation induced by TNF- $\alpha$ (Figure 2A). Conversely, F14 inhibited the accumulation of the mRNAs of CCL2 and CXCL10 "late" genes in response to TNF- $\alpha$ (Figure 6D, E).

CXCL8 and CXCL10 encode chemokines CXCL8 and CXCL10 (also known as IL-8 and IP10 , respectively) that are secreted from stimulated cells. Following induction of VACV protein expression (Figure $6 \mathrm{H}$ ) the levels of these chemokines were measured by ELISA and showed that secretion of CXCL10, but not CXCL8, was inhibited by F14. In contrast, the secretion of both chemokines was inhibited, or unaffected, by VACV proteins B14 or C6, respectively, as expected (Figure 6C, F). An inhibitor of IKK $\beta$, B14 inhibited the secretion of chemokines, whereas $\mathrm{C6}$, an inhibitor of IRF3 and type I IFN signalling, had a negligible effect (Figure 6C, F). Thus, unlike other VACV NF-kB inhibitors, F14 inhibits only a subset of NF- $\kappa B$-responsive genes.

\section{Acetylation of $p 65$ and recruitment of BRD4 are inhibited by F14}

Posttranslational modifications of p65 accompany NF-KB translocation to the nucleus and some, such as acetylation by acetyltransferases CBP and p300, are associated with increased transcriptional activity [[36, 37, 39]; reviewed by [13, 33, 34]]. F14 did not interfere with the phosphorylation of p65 at $\operatorname{Ser}^{536}$ (Figure 2A), and so the acetylation of p65 Lys ${ }^{310}$, was investigated. T-REx-293 cell lines that inducibly express F14 or contain the empty vector (EV) control were transfected with plasmids expressing p65 and CBP in the presence of the inducer, doxycycline. Although both cell lines expressed equivalent amounts of ectopic p65 and CBP, the amount of p65 acetylated at Lys ${ }^{310}$ was greatly diminished by F14 (Figure 7A). Quantitative analysis showed acetylated p65 was reduced $90 \%$ by F14 (Figure 7B). This result, together with the results presented in Figure 5, indicated that the reduced acetylation of $\mathrm{p} 65$ was due to disruption of the interaction between $\mathrm{p} 65$ and CBP by F14.

BRD4 docks onto acetylated histones and non-histone proteins and recruits transcriptional regulatory complexes to the chromatin [reviewed by [77]]. For instance, acetylated Lys ${ }^{310}$ on p65 serves as a docking site for the bromodomains 1 and 2 of BRD4, which then recruits PTEFb to promote RNAP II elongation during transcription of some NF- $\kappa B$-responsive genes [40]. The differential sensitivity of TNF- $\alpha$-stimulated genes to the inhibition of NF- $\kappa B$ by F14 might reflect the differential requirement of p65 acetylated at Lys ${ }^{310}$, and the subsequent recruitment of BRD4, to activate the expression from NF- $\mathrm{kB}$-responsive promoters [40]. This hypothesis was tested by chromatin immunoprecipitation with an anti-BRD4 antibody 
1 followed by quantitative PCR of the promoters of two representative genes: $N F K B I A$, 2 insensitive to $\mathrm{F} 14$ inhibition, and $C X C L 10$, sensitive to inhibition. BRD4 was recruited to both 3 promoters after TNF- $\alpha$ stimulation, with BRD4 present on NFKBIA promoter at 1 and $5 \mathrm{~h}$ 4 post-stimulation, whereas BRD4 was evident on CXCL10 promoter only at $5 \mathrm{~h}$ post5 stimulation, mirroring the kinetics of mRNA accumulation (Figure 7C; see Figure 6E). In the 6 presence of $\mathrm{F} 14$, the recruitment of BRD4 to NFKBIA promoter remained unaffected, whilst 7 its recruitment to CXCL10 was blocked (Figure 7C). This strongly suggests that inhibition of 8 acetylation of $\mathrm{p} 65$ at Lys ${ }^{310}$ by $\mathrm{F} 14$ is relayed downstream to the recruitment of BRD4 to the 9 "F14-sensitive" CXCL10 promoter, but not to the "F14-insensitive" NFKBIA promoter.

F14 is a unique viral antagonist of $N F-K B$

The TAD domain of p65 belongs to the class of acidic activation domains, characterised by a preponderance of Asp or Glu residues surrounding hydrophobic motifs [22]. VP16 is a transcriptional activator from herpes simplex virus (HSV) type 1 that bears a prototypical acidic TAD (Figure 8A) and inhibits the expression of virus-induced IFN- $\beta$ by association with p65 and IRF3 [78]. Although the VP16-mediated inhibition of the IFN- $\beta$ promoter was independent of its TAD, we revisited this observation to investigate the effect of VP16 more specifically on NF-kB-dependent gene activation. VP16 inhibited NF-kB reporter gene expression in a dose-dependent manner and deletion of the TAD reduced NF-KB inhibitory activity of VP16 about 2-fold, but some activity remained (Figure 8A).

A search for other viral proteins that contain motifs resembling the $\phi \times x \phi \phi$ motif present in acidic transactivation activation domains detected a divergent $\phi \times x \phi \phi$ motif in the protein E7 (aa 79-83) from the high-risk human papillomavirus (HPV) 16, with acidic residues upstream $\left(\mathrm{Asp}^{75}\right)$ or within $\left(\mathrm{Glu}^{80}\right.$ and Asp ${ }^{81}$ ) the motif (Figure $\left.8 \mathrm{~B}\right)$. E7 has been reported to inhibit NF$\mathrm{KB}$ activation, in addition to its role in promoting cell cycle progression [79-82]. We confirmed that HPV-16 protein E7 inhibits NF-KB-dependent gene expression, albeit to a lesser extent than VACV F14 or HSV-1 VP16 (Figure 8B). Furthermore, E7 mutants harbouring aa substitutions that inverted the charge of $A_{s p^{75}}(\mathrm{D} 75 \mathrm{~K})$ or added a positive charge to the otherwise hydrophobic Leu ${ }^{83}$ (L83R) were impaired in their capacity to inhibit NF-kB (Figure 8B).

Lastly, the ability of VP16 and E7 to associate with CBP was assessed after ectopic expression in HEK 293T cells. Neither VP16 nor E7, like VACV protein C6 used as negative control, co-precipitated CBP under conditions in which F14 did (Figure $8 \mathrm{C}$ ). These findings indicate that the mimicry of p65 TAD by F14 is a strategy unique among human pathogenic viruses to suppress the activation of NF-kB. 


\section{DISCUSSION}

The inducible transcription of NF-KB-dependent genes is a critical response to virus infection. After binding to $\mathrm{KB}$ sites in the genome, NF-KB promotes the recruitment of chromatin remodelling factors, histone-modifying enzymes, and components of the transcription machinery to couple the sensing of viral and inflammatory signals to the selective activation of the target genes. In response, viruses have evolved multiple evasion strategies, including interference with NF-KB activation. VACV is a paradigm in viral evasion mechanisms, inasmuch as this poxvirus encodes 15 proteins known to intercept the signalling cascades downstream of PRRs and cytokine receptors that activate NF-KB [reviewed by [50, 51], [83, 84]]. Nonetheless, a VACV strain lacking all these inhibitors still prevented NF-kB activation after p65 translocation into the nucleus [56] indicating the existence of other inhibitor(s).

Here VACV protein F14 is shown to inhibit NF-KB activation within the nucleus and its mechanism of action is elucidated. First, ectopic expression of F14 reduces NF-KBdependent gene expression stimulated by TNF- $\alpha$ or $\mathrm{IL}-1 \beta$ (Figure $1 \mathrm{~A}, \mathrm{~B}$ ). Second, F14 is expressed early during VACV infection, and is small enough $(8 \mathrm{kDa})$ to diffuse passively into the nucleus after expression in cytoplasmic viral factories (Figure 1E, H). Third, a VACV strain lacking both $\mathrm{A} 49$ and $\mathrm{F} 14$ (vv811 $\triangle \mathrm{A} 49 \Delta \mathrm{F} 14)$ is less able to suppress cytokinestimulated NF-KB-dependent gene expression than vv811 $\triangle \mathrm{A} 49$ (Figure 1I). Fourth, following TNF-a stimulation, IKBa degradation, IKK-mediated phosphorylation of p65 at $\mathrm{Ser}^{536}$ and p65 accumulation in the nucleus remained unaffected in the presence of F14 (Figure 2A, B). And fifth, F14 blocked NF-kB-dependent gene expression stimulated by p65 overexpression, indicating that it acts at or downstream of p65 (Figure 2C). Lastly, despite the presence of several other VACV encoded NF-kB inhibitors, the biological importance of F14 was illustrated by its contribution to virulence (Figure 1F, G), a feature shared with many immunomodulatory proteins from VACV, including some inhibitors of NF-KB [reviewed by $[50,51]]$.

Mechanistically, F14 inhibits NF-kB via a C-terminal 23 aa motif, resembling p65 acidic activation domain, which disrupts the binding of p65 to its coactivator CBP (Figures 4 and 5). Consequently, $\mathrm{F} 14$ reduces acetylation of $\mathrm{p} 65 \mathrm{Lys}^{310}$ and subsequent recruitment of BRD4 to the CXCL10 promoter, but not to the NFKBIA promoter (Figure 7). These findings correlated with F14 suppressing CXCL10 (and CCL2), but not NFKBIA (and CXCL8), mRNA expression (Figure $6 A, B, D, E)$. The selective inhibition of a subset of NF-kB-dependent genes by $\mathrm{F} 14$, despite the interference with molecular events deemed important for p65mediated transactivation, underscores the complexity of the nuclear actions of NF-kB. Initial understanding of NF-KB-mediated gene activation was derived mostly using artificial reporter plasmids, but subsequent genome-wide, high-throughput studies uncovered diverse mechanisms of gene activation [14, 16, 24, 29, 30, 85, 86]. Because multiple promoters containing $\mathrm{kB}$ sites are preloaded with $\mathrm{CBP} / \mathrm{p} 300$, RNAP II and general transcription factors, the activation of transcription by NF-KB relies on the recruitment of BRD4 [85, 86].

Recruitment of BRD4 to the promoters and enhancers occurs via bromodomain-mediated docking onto acetylated lysine residues on either histones or non-histone proteins and promotes RNAP II processivity [reviewed by [77]]. BRD4 is recruited to NF-kB-bound promoters via the recognition of p65 acetylated at Lys ${ }^{310}$ [40]. This explains the observation that BRD4 is less enriched on the CXCL10 promoter following TNF-a stimulation in the presence of $\mathrm{F} 14$, which is associated with the reduced acetylation of $\mathrm{p} 65$ by CBP (Figure 7A, $\mathrm{B}, \mathrm{D})$. Nonetheless, BRD4 enrichment on NFKBIA promoter remained unaffected in the presence of F14 (Figure 7C), suggesting the existence of alternative mechanisms of BRD4 
recruitment to the promoter of NF-kB-responsive genes. It is possible that acetylated histones mediate BRD4 recruitment to some NF-kB-bound promoters in the absence of acetylated p65. For instance, histone 4 acetylated on Lys ${ }^{5}$, Lys ${ }^{8}$ and Lys ${ }^{12}$ (H4K5/K8/K12ac) is responsible for BRD4 recruitment to NF-kB-responsive genes upon lipopolysaccharide stimulation [85]. Alternatively, the genes whose expression is insensitive to F14 might be activated independently of the p65 $\mathrm{TA}_{1}$ domain, as it is the case of some NF-kB-responsive genes in mouse fibroblasts stimulated with TNF-a, including Nfkbia. For those genes, p65 occupancy on the promoter elements suffices for gene activation, via recruitment of secondary transcription factors [24].

In the nucleus, p65 engages with multiple binding partners via its transactivation domains, including the direct interactions between $\mathrm{TA}_{1}$ and $\mathrm{TA}_{2}$ and the $\mathrm{KIX}$ and transcriptional adaptor zinc finger (TAZ) 1 domains of CBP, respectively. These interactions are mediated by hydrophobic contacts of the $\phi \times x \phi \phi$ motifs and complemented by electrostatic contacts by the acidic residues surrounding the hydrophobic motifs [74, 86]. Sequence analysis suggested that $\mathrm{F} 14$ mimics the p65 $\mathrm{TA}_{1}$ domain (Figure $3 \mathrm{~A}$ ). Indeed, fusion of the TAD-like domain of $\mathrm{F} 14$ to a p65 mutant lacking the $\mathrm{TA}_{1}$ domain restored its transactivation activity to wildtype levels (Figure $3 \mathrm{E}$ ). This explains a rather spurious observation from a yeast twohybrid screen of VACV protein-protein interactions, in which F14 could not be tested because it was found to be a strong activator when fused to the Gal4 DNA-binding domain [87]. Site-directed mutagenesis of $\mathrm{F} 14$ revealed that the dipeptide $\mathrm{Asp}^{62 / 63}$, but not Leu ${ }^{65}$ or $\mathrm{Leu}^{68}$ of the $\phi \times x \phi \phi$ motif, is required for inhibition of NF-KB (Figure 4A), for interaction with $\mathrm{CBP}$ (Figure 4B) and for the efficient disruption of p65 binding to CBP (Figure 5D). This contrasts with the molecular determinants of p65 TA 1 binding to the KIX domain of CBP, which is dependent on the hydrophobic residues of the $\phi x \times \phi \phi$ motif, particularly Phe ${ }^{542}$ [74]. In the future, solving the structure of F14 TAD-like domain in complex with the KIX domain will provide insight into this discrepancy and shed light on how VACV evolved to inhibit NF$\mathrm{KB}$ via molecular mimicry of p65 TAD. Nonetheless, the conservation of the Asp ${ }^{62 / 63}$ site in all orthopoxvirus species (Figure $3 \mathrm{~A}$ ) implies an important function.

The diminished acetylation of p65 Lys ${ }^{310}$ is a direct consequence of the disruption of CBP and p65 interaction by F14. Other poxvirus proteins are reported to inhibit p65 acetylation. For instance, ectopic expression of VACV protein K1 inhibited CBP-dependent p65 acetylation and NF-KB-dependent gene expression [88], whilst during infection, K1 inhibited NF-KB activation upstream of IKBa degradation [89]. Regardless whether K1 inhibits NF-KB upstream or downstream of p65, the vv811 $\triangle \mathrm{A} 49$ strain used to predict the existence of additional VACV inhibitors of NF-KB lacks K1 [56]. The other poxviral protein that inhibits CBP-mediated acetylation of $\mathrm{p} 65$, and thereby NF-kB activation, is encoded by gene 002 of orf virus, a parapoxvirus that causes mucocutaneous infections in goats and sheep [90]. However, protein 002 differs from F14 in that it interacts with p65 to prevent phosphorylation at p65 $\mathrm{Ser}^{276}$ and the subsequent acetylation at Lys ${ }^{310}$ by $\mathrm{p} 300[90,91]$.

F14 causes diminished p65 Lys ${ }^{310}$ acetylation and consequential reduced recruitment of BRD4 to CXCL10 promoter. The interaction between BRD4 and p65 can also reduce ubiquitylation and proteasomal degradation of nuclear p65 [92]. Thus, in addition to reducing BRD4 recruitment to the promoters of a subset of NF-KB-responsive genes, F14 could also destabilise nuclear p65 to terminate the pro-inflammatory signal. This represents an interesting avenue for future investigation. From the viral perspective, the selective inhibition of only a subset of NF-kB-responsive genes by F14 might represent an adaptation to more efficiently counteract the host immune response. If an NF-KB-activating signal reached the nucleus of an infected cell, maintaining expression of some NF-kB-dependent genes, particularly NFKBIA, might promote inhibition of pathway activation by IKBa. Newly 
synthesised IkBa not only tethers cytoplasmic NF-kB, but can also remove NF-kB from the DNA and cause its export from the nucleus $[17,18,93]$.

Our recent proteomic analysis of VACV infection revealed that both CBP and p300 are degraded in proteasome-dependent manner during infection [69]. The proteasomal degradation of $\mathrm{CBP} / \mathrm{p} 300$ might be an additional immune evasion strategy of VACV, given its role in the activation of gene expression downstream of NF-KB and other immune signalling pathways, like IRF3 [94] and IFN-stimulated JAK/STAT [95, 96]. Because of the widespread distribution of CBP/p300-binding sites in enhancer and promoter elements across the genome, one can predict that the VACV-induced downregulation of these histone acetyltransferases will have far-reaching consequences on the host gene expression (Wang et al., 2009).

This study adds VACV protein F14 to the list of viral binding partners of CBP and its paralogue p300, which includes adenovirus E1A protein [97], human immunodeficiency virus (HIV) 1 Tat protein [98], human T-cell lymphotropic virus (HTLV) 1 Tax protein [99], high-risk HPV E6 protein [100], and polyomavirus T antigen [101]. Despite the fact that some of these proteins also inhibit NF-kB activation [79, 100, 102], F14 is unique among them in mimicking p65 $\mathrm{TA}_{1}$ to bind to CBP and prevent its interaction with p65. After searching for additional viral proteins that might mimic p65 TAD, we focused on HPV E7 and HSV-1 VP16. The latter protein has a prototypical acidic TAD (Figure $8 \mathrm{~A}$ ), the former bears a motif resembling the $\phi x \times \phi \phi$ motif (Figure 8B), and both proteins inhibit NF-KB activation [78-82]. Data presented here confirm that VP16 and, to a lesser extent, E7 each inhibit NF-kB-dependent gene expression (Figure 8A, B). However, neither co-precipitated CBP under conditions in which F14 did (Figure $8 C$ ), suggesting VP16 and E7 inhibit NF-KB activation by a mechanism distinct from F14. The interaction between VP16 and CBP is contentious [21, 78] and data presented here suggest that these two proteins do not associate with each other under the conditions tested.

Overall, our search for additional inhibitors of NF-kB activation encoded by VACV unveiled a unique viral strategy to inhibit this transcription factor that is required for the host antiviral and inflammatory responses. The detailed mechanism of how the VACV protein F14 suppresses NF-KB activation is described. By mimicking the $\mathrm{TA}_{1}$ domain of p65, F14 disrupts the interaction between p65 and its coactivator CBP, thus inhibiting the downstream molecular events that trigger the activation of a subset of inflammatory genes in response to cytokine stimulation. Moreover, the contribution of $\mathrm{F} 14$ to virulence highlighted its physiological relevance. The molecular mimicry of F14 might be only rivalled by that of the avian reticuloendotheliosis virus, a retrovirus whose $v$-Rel gene was acquired from an avian host and modified to inhibit p65-dependent gene activation [reviewed by [103]]. 


\section{MATERIALS AND METHODS}

\section{Sequence analysis}

Candidate open reading frames (ORFs) encoding the unknown VACV inhibitor of NF-KB were first selected based on VACV genomes available on the NCBI database (accession numbers: NC_006998.1 for the Western Reserve strain, and M35027.1 for the Copenhagen strain). The prediction of molecular mass and isoelectric point ( $\mathrm{pl}$ ), and of nuclear localisation signal (NLS) sequences, of the candidate VACV gene products was done with ExPASy Compute pl/MW tool (https://web.expasy.org/compute pi/) and SeqNLS (http://mleg.cse.sc.edu/segNLS/, [104], respectively. Domain searches were performed using InterPro (http://www.ebi.ac.uk/interpro/search/sequence/), UniProt (https://www.uniprot.org/uniprot/), HHpred (https://toolkit.tuebingen.mpg.de/tools/hhpred), PCOILS (https://toolkit.tuebingen.mpg.de/tools/pcoils), and Phobius (https://www.ebi.ac.uk/Tools/pfa/phobius/) [105]. Gene family searches were done within the Pfam database (https://pfam.xfam.org/) and conservation within the poxvirus family, with Viral Orthologous Clusters (https://4virology.net/virology-ca-tools/vocs/) [72] and protein BLAST (https://blast.ncbi.nlm.nih.gov/Blast.cgi) searches. Phre2 (http://www.sbg.bio.ic.ac.uk/phyre2/html/page.cgi?id=index) [73] was used for the prediction of F14 protein structure. Multiple sequence alignments were performed using Clustal Omega (https://www.ebi.ac.uk/Tools/msa/clustalo/) and 3.0 (http://espript.ibcp.fr/ESPript/ESPript/) [106] was used for the visualisation of protein sequence alignments.

\section{Expression vectors}

The VACV F14L ORF (strain Western Reserve) was codon-optimised for expression in human cells and synthesised by GeneArt (Thermo Fisher Scientific), with an optimal 5' Kozak sequence and fused to an N-terminal FLAG epitope. For ease of subsequent subcloning, 5' BamHI and 3' Xbal restriction sites were included as well as a Notl site between the epitope tag and the ORF. For mammalian expression, N-terminal FLAG-tagged $\mathrm{F} 14$ was subcloned between the BamHI and Xbal restriction sites of a pcDNA4/TO vector (Invitrogen). Alternatively, codon-optimised F14 was PCR-amplified to include a 3' HA tag or a 3' FLAG or no epitope tag, and 5' BamHI and 3' Xbal sites to clone into pcDNA4/TO plasmid. In addition, codon-optimised F14 sequence was PCR-amplified to include 5' BamHI and 3' Notl sites to facilitate cloning into a pcDNA4/TO-based vector containing a TAP tag sequence after the Notl site; the TAP tag consisted of two copies of the Strep-tag II epitope and one copy of the FLAG epitope [107]. Mutant F14 expression vectors were constructed with QuikChange II XL Site-Directed Mutagenesis kit (Agilent), using primers containing the desired mutations and C-terminal TAP-tagged codon-optimised F14 cloned into pcDNA4/TO as template. Expression vectors for VACV proteins C6 and B14 have been described [64, 108].

The ORF encoding HPV16 E7 protein was amplified from a template kindly provided by Dr. Christian Kranjec and Dr. John Doorbar (Dept. Pathology, Cambridge, UK) and cloned into 5' BamHI and 3' Notl sites of a pcDNA4/TO-based vectors fused to a C-terminal TAP tag or HA epitope. Vectors expressing mutant E7 proteins were generated by site-directed mutagenesis as described above. The ORF encoding HSV-1 VP16 and $\triangle T A D$ mutant (lacking aa 413-490) were amplified from a pEGFP-C2-based VP16 expression plasmid kindly provided by Dr. Colin Crump (Dept. Pathology, Cambridge, UK) and cloned into 5' BamHI and 3' Notl sites of a pcDNA4/TO-based vector fused to a C-terminal HA epitope. 
1 Plasmids encoding TAP- and HA-tagged p65 were described elsewhere [83] and plasmids

2 expressing FLAG-tagged mouse CBP, and HA-tagged mouse CBP were kind gift from Prof.

3 Gerd A. Blobel (University of Pennsylvania, Philadelphia, USA) and Prof. Tony Kouzarides

4 (Dept. Pathology and The Gurdon Institute, Cambridge, UK). Firefly luciferase reporter

5 plasmids for NF-KB, ISRE and AP-1, as well as the constitutively active TK-Renilla luciferase

6 reporter plasmid were kind gifts from Prof. Andrew Bowie (Trinity College, Dublin, Republic

7 of Ireland).

8 The oligonucleotide primers used for cloning and site-directed mutagenesis are listed in 9 Table S1. Nucleotide sequences of the inserts in all the plasmids were verified by Sanger 10 DNA sequencing.

\section{Cell lines}

All cell lines were grown in medium supplemented with $10 \%$ foetal bovine serum (FBS, Pan Biotech), 100 units $/ \mathrm{mL}$ of penicillin and $100 \mu \mathrm{g} / \mathrm{mL}$ of streptomycin (Gibco), at 37ロC in a humid atmosphere containing $5 \% \mathrm{CO}_{2}$. Human embryo kidney (HEK) 293T epithelial cells, and monkey kidney BS-C-1 and CV-1 epithelial cells were grown in Dulbecco's modified Eagle's medium (DMEM, Gibco). Rabbit kidney RK13 epithelial cells were grown in minimum essential medium (MEM, Gibco) and human cervix HeLa epithelial cells, in MEM supplemented with non-essential amino acids (Gibco). T-REx-293 cells (Invitrogen) were grown in DMEM supplemented with blasticidin $(10 \mu \mathrm{g} / \mathrm{mL}$, InvivoGen), whilst the growth medium of T-REx-293-derived cell lines stably transfected with pcDNA4/TO-based plasmids was further supplemented with zeocin $(100 \mu \mathrm{g} / \mathrm{mL}$, Gibco).

The absence of mycoplasma contamination in the cell cultures was tested routinely with MycoAlert detection kit (Lonza), following the manufacturer's recommendations.

Construction of recombinant viruses

A VACV Western Reserve (WR) strain lacking F14 (vDF14) was constructed by introduction of a 137-bp internal deletion in the F14L ORF by transient dominant selection [109]. A DNA fragment including the first $3 \mathrm{bp}$ of $F 14 L$ ORF and 297 bp upstream, intervening Notl and Hindlll sites, and the last $82 \mathrm{bp}$ of the ORF and $218 \mathrm{bp}$ downstream were generated by overlapping PCR and inserted into the Pstl and BamHI sites of pUC13-Ecogpt-EGFP plasmid, containing the Escherichia coli guanylphosphoribosyl transferase (Ecogpt) gene fused in-frame with the enhanced green fluorescent protein (EGFP) gene under the control of the VACV $7.5 \mathrm{~K}$ promoter [68]. The resulting plasmid contained an internal deletion of the F14L ORF (nucleotide positions 42049-42185 from VACV WR reference genome, accession number NC_006998.1). The remaining sequence of F14L was out-of-frame and contained multiple stop codons, precluding the expression of a truncated version of F14. The derived plasmid was transfected into CV-1 cells that had been infected with VACV-WR at 0.1 p.f.u./cell for $1 \mathrm{~h}$. After $48 \mathrm{~h}$, progeny viruses that incorporated the plasmid by recombination and expressed the Ecogpt-EGFP were selected and plaque-purified three times on monolayers of BS-C-1 cells in the presence of mycophenolic acid $(25 \mu \mathrm{g} / \mathrm{mL})$, supplemented with hypoxanthine $(15 \mu \mathrm{g} / \mathrm{mL})$ and xanthine $(250 \mu \mathrm{g} / \mathrm{mL})$. The intermediate recombinant virus was submitted to three additional rounds of plaque purification in the absence of the selecting drugs and GFP-negative plaques were selected. Under these conditions, progeny viruses can undergo a second recombination that result in loss of the Ecogpt-EGFP cassette concomitantly with either incorporation of the desired mutation $(v \Delta \mathrm{F} 14)$ or reversal to wild 
type genotype ( $\mathrm{vF} 14)$. Because $\mathrm{v} \Delta \mathrm{F} 14$ and $\mathrm{vF} 14$ are sibling strains derived from the same intermediate virus, they are genetically identical except for the 137-bp deletion in the $F 14 L$ locus. Viruses were analysed by PCR to identify recombinants by distinguishing wild type and $\Delta \mathrm{F} 14$ alleles, and the presence or absence of the Ecogpt-EGFP cassette.

To restore F14 expression in $\mathrm{v} \triangle \mathrm{F} 14$, the $F 14 L$ locus was amplified by PCR, including about $250 \mathrm{bp}$ upstream and downstream of the ORF, and inserted into the Pstl and BamHI sites of pUC13-Ecogpt-EGFP plasmid. Additionally, F14L ORF fused to the sequence coding a Cterminal TAP tag was also amplified by overlapping PCR, including the same flanking sequences described above, and inserted into the Pstl and BamHI sites of pUC13-EcogptEGFP plasmid. By using the same transient dominant selection method, these plasmids were used to generate two revertant strains derived from $v \Delta \mathrm{F} 14$ : (i) $v F 14-R e v$, in which $\mathrm{F} 14$ expression from its natural locus was restored, and (ii) vF14-TAP, expressing F14 fused to a C-terminal TAP tag under the control of its natural promoter. The vC6-TAP virus was described elsewhere [108].

A VACV vv811 strain lacking both A49 and F14 (vv811 $\Delta$ A49 $\Delta \mathrm{F} 14)$ was also constructed by transient dominant selection. The resultant virus contained the same 137-bp internal deletion in the F14L ORF within the vv811 $\triangle \mathrm{A} 49$ strain generated previously [56]. The distinction between wild type and $\triangle \mathrm{F} 14$ alleles in the obtained viruses, and the presence or absence of the Ecogpt-EGFP cassette, was determined by PCR analysis.

The oligonucleotide primers used to generate the recombinant VACV strains are listed in Table S1. To verify that all the final recombinant viruses harboured the correct sequences, PCR fragments spanning the $F 14 L$ locus were sequenced.

\section{Preparation of virus stocks}

The stocks of virus strains derived from VACV WR were prepared in RK-13 cells. Cells grown to confluence in T-175 flasks were infected at 0.01 p.f.u./cell until complete cytopathic effect was visible. The cells were harvested by centrifugation, suspended in a small volume of DMEM supplemented with $2 \%$ FBS, and submitted to multiple cycles of freezing/thawing and sonication to lyse the cells and disrupt aggregates of virus particles and cellular debris. These crude virus stocks were used for experiments in cultured cells. Crude stocks of vv811 and derived strains were prepared in the same way, except for the BS-C-1 cells used for infection. For the in vivo work, virus stocks were prepared by ultracentrifugation of the cytoplasmic fraction of infected cell lysates through sucrose cushion and suspension of the virus samples in $10 \mathrm{mM}$ Tris- $\mathrm{HCl} \mathrm{pH} 9.0$ [110]. The viral titres in the stocks were determined by plaque assay on BS-C-1 cells.

\section{Virus growth and spread assays}

To analyse virus growth properties in cell culture, single-step growth curve experiments were performed in HeLa cells. Cells were grown to about $90 \%$ confluence in T-25 flasks and then infected at 5 p.f.u./cell in growth medium supplemented with 2\% FBS. Virus adsorption was at $37 \square \mathrm{C}$ for $1 \mathrm{~h}$. Then the inoculum was removed, and the cells were replenished with growth medium supplemented with $2 \%$ FBS. At 1, 8, and $24 \mathrm{~h} \mathrm{p.i.,} \mathrm{infected-cell} \mathrm{supernatants}$ and monolayers were collected for determination of extracellular and cell-associated infectious virus titres by plaque assay on BS-C- 1 cells. Supernatants were clarified by centrifugation to remove cellular debris and detached cells, whereas cell monolayers were 
1

scraped and disrupted by three cycles of freezing/thawing followed by sonication, to release intracellular virus particles.

The virus spread in cell culture was assessed by plaque formation. Confluent monolayers of BS-C-1 cells in 6-well plates were infected with 50 p.f.u./well and overlaid with MEM supplemented with $2 \%$ FBS and $1.5 \%$ carboxymethylcellulose. After $48 \mathrm{~h}$, infected cell monolayers were stained with $0.5 \%$ crystal violet solution in $20 \%$ methanol and imaged.

\section{Construction of inducible F14-expressing T-REx-293 cell line}

T-REx-293 cells (Invitrogen), which constitutively expresses the Tet repressor (TetR) under the control of the human cytomegalovirus (HCMV) immediate early promoter, were transfected with pcDNA4/TO-coF14-TAP plasmid, which encodes human codon-optimised F14 fused to a C-terminal TAP tag under the control of the HCMV immediate early promoter and two tetracycline operator $2\left(\mathrm{TetO}_{2}\right)$ sites. Transfected cells were selected in the presence of blasticidin $(10 \mu \mathrm{g} / \mathrm{mL})$ and zeocin $(100 \mu \mathrm{g} / \mathrm{mL})$ and clonal cell lines were obtained by limiting dilution. Expression of protein F14 within these clones was analysed by immunoblotting and flow cytometry with anti-FLAG antibodies.

\section{Reporter gene assays}

HEK 293 T cells in 96-well plates were transfected in quadruplicate with firefly luciferase reporter plasmid (NF-kB, ISRE, or AP-1), TK-Renilla luciferase reporter plasmid (as an internal control) and the desired expression vectors or empty vector (EV) using TransIT-LT1 transfection reagent (Mirus Bio), according to the manufacturer's instruction. On the following day, cells were stimulated with TNF-a $(10 \mathrm{ng} / \mathrm{ml}$, PeproTech) or IL-1 $\beta(20 \mathrm{ng} / \mathrm{ml}$, PeproTech) for $8 \mathrm{~h}$ (for NF-kB activation), IFN-a2 (1000 U/ml, PeproTech) for $8 \mathrm{~h}$ (for JAK/STAT/ISRE activation), or phorbol 12-myristate 13-acetate $(10 \mathrm{ng} / \mathrm{ml}$ ) for $24 \mathrm{~h}$ (for MAPK/AP-1 activation). Alternatively, NF-KB was activated by co-transfection of p65overexpressing plasmid and cells were harvested $24 \mathrm{~h}$ after transfection.

To measure NF-kB activation during infection, A549 cells transduced with a lentiviral vector expressing the firefly luciferase under the control of an NF-kB promoter (A549-NF-kB-Luc) [56] were grown in 96-well plates and infected with VACV vv811 and derived strains at 5 p.f.u./cell. After $6 \mathrm{~h}$, cells were stimulated with TNF-a $(10 \mathrm{ng} / \mathrm{ml}$, PeproTech) or IL-1 $\beta$ (20 $\mathrm{ng} / \mathrm{ml}$, PeproTech) for an additional $6 \mathrm{~h}$. In parallel, A549-NF-kB-Luc cells grown in 6-well plates were infected with the equivalent amount of virus for $12 \mathrm{~h}$ and cell lysates were analysed by immunoblotting.

Cells were lysed using passive lysis buffer (Promega) and firefly and Renilla luciferase luminescence was measured using a FLUOstar luminometer (BMG). Promoter activity was obtained by calculation of firefly/Renilla luciferase ratios and the promoter activity under pathway stimulation was normalised to the activity of the respective non-stimulated control of each protein under test. In parallel, aliquots of the replicas of each condition tested were combined, mixed with $5 \times$ SDS-polyacylamide gel loading buffer, and immunoblotted to confirm the expression of the proteins tested.

\section{Virus infection in cell culture}


HeLa or HEK 293T cells in 6-well plates (for protein expression analyses) or 10-cm dishes (for immunoprecipitation experiments) were infected at 5 p.f.u./cell. Viral inocula were prepared in growth medium supplemented with $2 \%$ FBS. Viral adsorption was done at $37 \square \mathrm{C}$ for $1 \mathrm{~h}$, after which the medium supplemented with $2 \%$ FBS was topped up to the appropriate vessel volume and cells were incubated at $37 \square \mathrm{C}$.

\section{In vivo experiments}

All animal experiments were conducted according to the Animals (Scientific Procedures) Act 1986 under the license PPL 70/8524. Mice were purchased from Envigo and housed in specific pathogen-free conditions in the Cambridge University Biomedical Services facility.

For the intradermal (i.d.) model of infection, female C57BL/6 mice (6-8-week old) were inoculated with $10^{4}$ p.f.u. in both ear pinnae and the diameter of the lesion was measured daily using a micrometer [111]. For the intranasal (i.n.) model, female BALB/c mice (6-8week old) were inoculated $5 \times 10^{3}$ p.f.u. divided equally into each nostril and were weighed daily [112]. In both cases, viral inocula were prepared in phosphate-buffered saline (PBS) supplemented with $0.01 \%$ bovine serum albumin (BSA, Sigma Aldrich) and the infectious titres in the administered inocula were confirmed by plaque assay.

For quantification of virus replication after the i.d. infection, infected mice were culled 3, 7, and $10 \mathrm{~d}$ p.i. and ear tissues were collected, homogenised and passed through a $70-\mu \mathrm{m}$ nylon mesh using DMEM containing 10\% FBS. Samples were frozen and thawed three times, sonicated thoroughly to liberate cell-associated virus particles, and the infectious titres present were determined by plaque assay on BS-C-1 cells.

\section{Immunoblotting}

For analysis of protein expression, cells were washed with ice-cold PBS and lysed on ice with cell lysis buffer [50 mM Tris- $\mathrm{HCl} \mathrm{pH} 8.0,150 \mathrm{mM} \mathrm{NaCl}, 1 \mathrm{mM}$ EDTA, 10\% (v/v) glycerol, $1 \%(\mathrm{v} / \mathrm{v})$ Triton X-100 and $0.05 \%(\mathrm{v} / \mathrm{v})$ Nonidet P-40 (NP-40)], supplemented with protease (cOmplete Mini, Roche) and phosphatase inhibitors (PhosSTOP, Roche), for 20 min. Lysed cells were scraped and lysates were clarified to remove insoluble material by centrifugation at $17,000 \times \mathrm{g}$ for $15 \mathrm{~min}$ at $4 \square \mathrm{C}$. Protein concentration in the cell lysate was determined using a bicinchoninic acid protein assay kit (Pierce). After mixing with $5 \times$ SDS-gel loading buffer and boiling at $100 \square \mathrm{C}$ for $5 \mathrm{~min}$, equivalent amounts of protein samples were loaded onto SDS-polyacrylamide gels or NuPAGE 4 to $12 \%$ Bis-Tris precast gels (Invitrogen), separated by electrophoresis and transferred onto nitrocellulose membranes (GE Healthcare). Membranes were blocked at room temperature with either $5 \%(\mathrm{w} / \mathrm{v})$ non-fat milk or $3 \%(\mathrm{w} / \mathrm{v})$ BSA (Sigma Aldrich) in Tris-buffered saline (TBS) containing $0.1 \%(\mathrm{v} / \mathrm{v})$ Tween20. To detect the expression of the protein under test, the membranes were incubated with specific primary antibodies diluted in blocking buffer at $4 \square \mathrm{C}$ overnight. After washing with TBS containing $0.1 \%(\mathrm{v} / \mathrm{v})$ Tween-20, membranes were probed with fluorophore-conjugated secondary antibodies (LI-COR Biosciences) diluted in $5 \%(\mathrm{w} / \mathrm{v})$ non-fat milk at room temperature for $1 \mathrm{~h}$. The antibodies used for immunoblotting are listed in Table S2. After washing, membranes were imaged using the Odyssey CLx imaging system (LI-COR Biosciences), according to the manufacturer's instructions. For quantitative analysis of protein levels, the band intensities on the immunoblots were quantified using the Image Studio software (LI-COR Biosciences). 


\section{Co-immunoprecipitation and pulldown assays}

HEK 293T or HeLa cells in 10-cm dishes were infected at 5 p.f.u./cell for 8 h or transfected overnight with the specified epitope-tagged plasmids using polyethylenimine (PEI, Polysciences, $2 \mu \mathrm{l}$ of $1 \mathrm{mg} / \mathrm{ml}$ stock per $\mu \mathrm{g}$ of plasmid DNA). For the competition assays, cells were starved of FBS for $3 \mathrm{~h}$ and stimulated with TNF-a (40 ng/ml, PeproTech) in FBSfree DMEM for 15 min before harvesting. Cells were washed twice with ice-cold PSB, scraped in immunoprecipitation (IP) buffer (50 mM Tris- $\mathrm{HCl} \mathrm{pH} \mathrm{7.4,} 150 \mathrm{mM} \mathrm{NaCl}, 0.5 \%$ (v/v) NP-40), $0.1 \mathrm{mM}$ EDTA), supplemented with protease (cOmplete Mini, Roche) and phosphatase (PhosSTOP, Roche) inhibitors, on ice, transferred to $1.5-\mathrm{ml}$ microcentrifuge tubes and rotated for $30 \mathrm{~min}$ at $4 \square \mathrm{C}$. Cell lysates were centrifuged at $17,000 \times \mathrm{g}$ for $15 \mathrm{~min}$ at $4 \square \mathrm{C}$ and the soluble fractions were incubated with $20 \mu \mathrm{l}$ of one of the following affinity resins equilibrated in IP buffer: (i) anti-FLAG M2 (Sigma Aldrich) for IP of FLAG- or TAPtagged proteins; (ii) anti-HA (Sigma Aldrich) for IP of HA-tagged proteins; or (iii) Strep-Tactin Superflow resin (IBA) for pulldown of TAP-tagged protein via Strep-tag II epitope. After $2 \mathrm{~h}$ of rotation at $4 \square \mathrm{C}$, the protein-bound resins were washed three times with ice-cold IP buffer. The bound proteins were eluted by incubation with $2 \times$ SDS-gel loading buffer and boiled at $100 \square \mathrm{C}$ for $5 \mathrm{~min}$ before analysis by SDS-polyacrylamide gel electrophoresis and immunoblotting, along with $10 \%$ input samples collected after clarification of cell lysates.

\section{Reverse transcription and quantitative PCR}

To analyse mRNA expression of NF-kB-responsive genes, T-REx-293-F14 and T-REx-293C6 cells in 12-well plates were induced overnight with $100 \mathrm{ng} / \mathrm{ml}$ doxycycline (Melford, UK) to induce the expression of the VACV proteins. The next day, cells were starved for $3 \mathrm{~h}$ by removal of serum from the medium and then stimulated in duplicate with TNF-a $(40 \mathrm{ng} / \mathrm{ml}$, PeproTech) in FBS-free DMEM for 0, 1 or $6 \mathrm{~h}$. RNA was extracted using RNeasy Mini Kit (Qiagen) and complementary DNA (cDNA) was synthesised using SuperScript III reverse transcriptase (Invitrogen) and oligo-dT primers (Thermo Scientific), according to the instructions of the respective manufacturers. The mRNA levels of CCL2, CXCL8, CXCL10, GAPDH and NFKBIA were quantified by quantitative PCR using gene-specific primer sets, fast SYBR green master mix (Applied Biosystems) and the ViiA 7 real-time PCR system (Life Technologies). The oligonucleotide primers used for the qPCR analysis of gene expression are listed in Table S1. Fold-induction of the NF-KB-responsive genes was calculated by the $2^{-\triangle \Delta C t}$ method using non-stimulated T-REx-293-C6 as the reference sample and GAPDH as the housekeeping control gene.

\section{Enzyme-linked immunosorbent assay (ELISA)}

The secretion of CXCL8 and CXCL10 was measured by ELISA. T-REx-293-EV, T-REx-293B14, T-REx-293-C6 and T-REx-293-F14 cells in 12-well plates were incubated overnight in the presence or absence of $100 \mathrm{ng} / \mathrm{ml}$ doxycycline (Melford, UK) to induce VACV protein expression. The next day, cells were stimulated in triplicate with TNF-a $(40 \mathrm{ng} / \mathrm{ml}$, PeproTech) in DMEM supplemented with $2 \%$ FBS for $16 \mathrm{~h}$. The supernatants were assayed for human CXCL8 and CXCL10 using the respective DuoSet ELISA kits (R\&D Biosystems), according to the manufacturer's instructions. 
For immunofluorescence microscopy, T-REx-293-EV, T-REx-293-B14, T-REx-293-C6 and T-REx-293-F14 cells on poly-D-lysine-treated glass coverslips placed inside 6-well plates. Following induction of protein expression with $100 \mathrm{ng} / \mathrm{ml}$ doxycycline (Melford, UK) overnight, cells were starved of serum for $3 \mathrm{~h}$ and then stimulated with $40 \mathrm{ng} / \mathrm{ml}$ TNF- $\alpha$ (PeproTech) in FBS-free DMEM for $15 \mathrm{~min}$. At the moment of harvesting, the cells were washed twice with ice-cold PBS and fixed in 4\% (v/v) paraformaldehyde. After quenching of free formaldehyde with $150 \mathrm{mM}$ ammonium chloride, the fixed cells were permeabilised with $0.1 \%(\mathrm{v} / \mathrm{v})$ Triton X-100 in PBS and blocked with $10 \%(\mathrm{v} / \mathrm{v})$ FBS in PBS. Antibody staining was carried out with mouse anti-p65 (Santa Cruz) and rabbit anti-FLAG (Sigma Aldrich) antibodies for $1 \mathrm{~h}$, followed by incubation with the appropriate AlexaFluor fluorophoreconjugated secondary antibodies (Invitrogen Molecular Probes) and mounting onto glass slides with Mowiol 4-88 (Calbiochem) containing $0.5 \mu \mathrm{g} / \mathrm{ml}$ DAPI (4',6-diamidino-2phenylindole, Sigma Aldrich). The antibodies used for immunofluorescence are listed in Table S2. Images were acquired on an LSM 700 confocal microscope (Zeiss) using ZEN system software (Zeiss). Quantification of nuclear localisation of p65 was done manually on the ZEN lite (blue edition, Zeiss).

\section{Chromatin immunoprecipitation and quantitative PCR (ChIP-qPCR)}

T-REx-F14 cells in 15-cm dishes were incubated overnight in the absence or in the presence of $100 \mathrm{ng} / \mathrm{ml}$ doxycycline (Melford, UK) to induce F14 expression. The next day, cells were starved of FBS for $3 \mathrm{~h}$ and stimulated with TNF- $\alpha(40 \mathrm{ng} / \mathrm{ml}$, PeproTech) in FBS-free DMEM for 0,1 or $5 \mathrm{~h}$. Cells were crosslinked with $1 \%(\mathrm{v} / \mathrm{v})$ formaldehyde added directly to the growth medium. After $10 \square \mathrm{min}$ at room temperature, crosslinking was stopped by the addition of $0.125 \square \mathrm{M}$ glycine. Cells were then lysed in $0.2 \% \mathrm{NP}-40,10 \mathrm{mM}$ Tris- $\mathrm{HCl} \mathrm{pH} 8.0$, $10 \mathrm{mM} \mathrm{NaCl}$, supplemented with protease (cOmplete Mini, Roche), phosphatase (PhosSTOP, Roche) and histone deacetylase (10 mM sodium butyrate, Sigma Aldrich) inhibitors, and nuclei were recovered by centrifugation at $600 \times \mathrm{g}$ for $5 \mathrm{~min}$ at $4 \square \mathrm{C}$. To prepare the chromatin, nuclei were lysed in $1 \%(\mathrm{w} / \mathrm{v}) \mathrm{SDS}, 50 \square \mathrm{mM}$ Tris $-\mathrm{HCl} \mathrm{pH} \square 8.0$, $10 \square \mathrm{mM}$ EDTA, plus protease/phosphatase/histone acetylase inhibitors, and lysates were sonicated in a Bioruptor Pico (Diagenode) to achieve DNA fragments of about $500 \square \mathrm{bp}$. After sonication, samples were centrifuged at $3,500 \times \mathrm{g}$ for $10 \mathrm{~min}$ at $4 \square \mathrm{C}$ and supernatants were diluted four-fold in IP dilution buffer [20 mM Tris- $\mathrm{HCl} \mathrm{pH} \mathrm{8.0,150} \mathrm{mM} \mathrm{NaCl,} 2 \mathrm{mM}$ EDTA, 1\% $(\mathrm{v} / \mathrm{v})$ Triton $\mathrm{X}-100,0.01 \%(\mathrm{w} / \mathrm{v})$ SDS] supplemented with protease/phosphatase/histone acetylase inhibitors.

Protein G-conjugated agarose beads (GE Healthcare) equilibrated in IP dilution buffer were used to preclear the chromatin for $1 \square \mathrm{h}$ at $4 \square \mathrm{C}$ with rotation. Before the immunoprecipitation, $20 \%$ of the precleared chromatin was kept as input control. Immunoprecipitation was performed with $8 \mu \mathrm{g}$ of anti-BRD4 antibody (Cell Signalling Technology, \#13440) or anti-GFP (Abcam, \#ab290), used as negative lgG control, overnight $4 \square C$ with rotation. Protein-DNA immunocomplexes were retrieved by incubation with $60 \mu \mathrm{l}$ of equilibrated protein Gconjugated agarose beads (GE Healthcare), for $2 \square \mathrm{h}$ at $4 \square \mathrm{C}$, followed by centrifugation at $5,000 \times \mathrm{g}$ for $2 \mathrm{~min}$ at $4 \square \mathrm{C}$. Immunocomplex-bound beads were then washed: (i) twice with IP wash I [20 mM Tris- $\mathrm{HCl} \mathrm{pH}$ 8.0, $50 \mathrm{mM} \mathrm{NaCl}, 2 \mathrm{mM}$ EDTA, 1\% (v/v) Triton X-100, 0.1\% (w/v) SDS]; (ii) once with IP wash buffer II [10 mM Tris-HCl pH 8.0, $250 \mathrm{mM} \mathrm{LiCl,} 1 \mathrm{mM}$ EDTA, $1 \%(\mathrm{v} / \mathrm{v})$ NP-40, 1\% (w/v) sodium deoxycholate]; and (iii) twice with TE buffer (10 mM Tris-HCI pH 8.0, 1 mM EDTA). Antibody-bound chromatin was eluted with 1\% SDS, $100 \mathrm{mM}$ 
1

2

3

4

5

6

7

sodium bicarbonate for $15 \mathrm{~min}$ at room temperature. Formaldehyde crosslinks were reversed by incubation overnight at $67 \square \mathrm{C}$ in presence of $1 \mu \mathrm{g}$ of RNase $\mathrm{A}$ and $300 \mathrm{mM} \mathrm{NaCl}$, followed by proteinase $\mathrm{K}$ digestion for $2 \mathrm{~h}$ at $45 \square \mathrm{C}$. Co-immunoprecipitated DNA fragments were purified using the QIAquick PCR purification kit (Qiagen) and analysed by quantitative PCR targeting the promoter elements of NFKBIA and CXCL10 containing $\mathrm{KB}$ sites. The oligonucleotide primers used for the QPCR analysis of ChIP are listed in Table S1. For display of the ChIP-qPCR data, the signals obtained from the ChIP with each antibody were divided by the signals obtained from the corresponding input sample.

\section{Statistical analysis}

Experimental data are presented as means + s.d. or means \pm s.e.m. for in vivo results, unless otherwise stated in figure legends. Statistical significance was calculated by twotailed unpaired Student's t-test. GraphPad Prism software (version 8.4.2) was used for statistical analysis. 


\section{ACKNOWLEDGEMENTS}

2 The authors thank Rachel Seear, Stephanie Macilwee, and Jemma Milburn for technical 3 support. We also thank John Doorbar (Dept. Pathology, University of Cambridge, UK), Colin 4 Crump (Dept. Pathology, University of Cambridge, UK), Tony Kouzarides (Dept. Pathology 5 and The Gurdon Institute, University of Cambridge, UK), and Gerd Blobel (University of 6 Pennsylvania, Philadelphia, USA) for providing us with reagents. We are also grateful to

7 Tony Kouzarides for helpful advice and to Callum Talbot-Cooper for critical reading of the 8 manuscript.

10 FUNDING

11 This work was supported by grant 090315 from the Wellcome Trust (to G.L.S.). J.D.A. was a 12 postdoctoral fellow of the Science without Borders programme from CNPq-Brazil (grant 13 235246/2014-0).

15 AUTHOR CONTRIBUTION

16 Conceptualisation: JDA, AAT, GLS

17 Methodology: JDA, HR, AAT, EVS, CAM, AJB

18 Software: N/A

19 Validation: JDA, HR, AAT, EVS

20 Formal Analysis: JDA, HR

21 Investigation: JDA, HR, AAT, EVS

22 Resources: AAT, CAM, AJB, GLS

23 Data Curation: JDA

24 Writing - Original Draft Preparation: JDA

25 Writing - Review and Editing: JDA, HR, AAT, CAM, AJB, GLS

26 Visualisation: JDA

27 Supervision: JDA, GLS

28 Project Administration: JDA, GLS

29 Funding: JDA, GLS 
1

3

4

5

6

7

8

9

10

11

12

13

14

15

16

17

18

19

20

21

22

23

24

25

26

27

28

29

30

31

32

33

34

35

36

37

38

39

40

41

42

43

44

45

46

47

48

49

50

\section{REFERENCES}

1. Elde, N.C., et al., Protein kinase R reveals an evolutionary model for defeating viral mimicry. Nature, 2009. 457(7228): p. 485-9.

2. Hancks, D.C., et al., Overlapping Patterns of Rapid Evolution in the Nucleic Acid Sensors cGAS and OAS1 Suggest a Common Mechanism of Pathogen Antagonism and Escape. PLoS Genet, 2015. 11(5): p. e1005203.

3. Alves, J.M., et al., Parallel adaptation of rabbit populations to myxoma virus. Science, 2019. 363(6433): p. 1319-1326.

4. Medzhitov, R., Recognition of microorganisms and activation of the immune response. Nature, 2007. 449(7164): p. 819-26.

5. Iwasaki, A., A virological view of innate immune recognition. Annu Rev Microbiol, 2012. 66: p. 177-96.

6. Griffith, J.W., C.L. Sokol, and A.D. Luster, Chemokines and chemokine receptors: positioning cells for host defense and immunity. Annu Rev Immunol, 2014. 32: p. 659-702.

7. Netea, M.G., et al., A guiding map for inflammation. Nat Immunol, 2017. 18(8): p. 826-831.

8. Altan-Bonnet, G. and R. Mukherjee, Cytokine-mediated communication: a quantitative appraisal of immune complexity. Nat Rev Immunol, 2019. 19(4): p. 205-217.

9. Bonilla, F.A. and H.C. Oettgen, Adaptive immunity. J Allergy Clin Immunol, 2010. 125(2 Suppl 2): p. S33-40.

10. Hayden, M.S. and S. Ghosh, Signaling to NF-kappaB. Genes Dev, 2004. 18(18): p. 2195-224.

11. Vallabhapurapu, S. and M. Karin, Regulation and function of NF-kappaB transcription factors in the immune system. Annu Rev Immunol, 2009. 27: p. 693-733.

12. Brubaker, S.W., et al., Innate immune pattern recognition: a cell biological perspective. Annu Rev Immunol, 2015. 33: p. 257-90.

13. Chen, L.F. and W.C. Greene, Shaping the nuclear action of NF-kappaB. Nat Rev Mol Cell Biol, 2004. 5(5): p. 392-401.

14. Kaikkonen, M.U., et al., Remodeling of the enhancer landscape during macrophage activation is coupled to enhancer transcription. Mol Cell, 2013. 51(3): p. 310-25.

15. Tian, B., D.E. Nowak, and A.R. Brasier, A TNF-induced gene expression program under oscillatory NF-kappaB control. BMC Genomics, 2005. 6: p. 137.

16. Zhao, M., et al., Transcriptional outcomes and kinetic patterning of gene expression in response to NF-kappaB activation. PLoS Biol, 2018. 16(9): p. e2006347.

17. Huang, T.T., et al., $A$ nuclear export signal in the $\mathrm{N}$-terminal regulatory domain of IkappaBalpha controls cytoplasmic localization of inactive NF-kappaB/lkappaBalpha complexes. Proc Natl Acad Sci U S A, 2000. 97(3): p. 1014-9.

18. Johnson, C., D. Van Antwerp, and T.J. Hope, An N-terminal nuclear export signal is required for the nucleocytoplasmic shuttling of IkappaBalpha. EMBO J, 1999. 18(23): p. 6682-93.

19. Barboric, M., et al., NF-kappaB binds P-TEFb to stimulate transcriptional elongation by RNA polymerase II. Mol Cell, 2001. 8(2): p. 327-37.

20. Gerritsen, M.E., et al., CREB-binding protein/p300 are transcriptional coactivators of $p 65$. Proc Natl Acad Sci U S A, 1997. 94(7): p. 2927-32.

21. Naar, A.M., et al., Composite co-activator ARC mediates chromatin-directed transcriptional activation. Nature, 1999. 398(6730): p. 828-32.

22. Schmitz, M.L., et al., Interaction of the $\mathrm{COOH}$-terminal transactivation domain of p65 NFkappa B with TATA-binding protein, transcription factor $\| B$, and coactivators. J Biol Chem, 1995. 270(13): p. 7219-26.

23. Sheppard, K.A., et al., Transcriptional activation by NF-kappaB requires multiple coactivators. Mol Cell Biol, 1999. 19(9): p. 6367-78.

24. van Essen, D., et al., Two modes of transcriptional activation at native promoters by NFkappaB p65. PLoS Biol, 2009. 7(3): p. e73. 
25. Saccani, S., S. Pantano, and G. Natoli, Modulation of NF-kappaB activity by exchange of dimers. Mol Cell, 2003. 11(6): p. 1563-74.

26. Thanos, D. and T. Maniatis, Virus induction of human IFN beta gene expression requires the assembly of an enhanceosome. Cell, 1995. 83(7): p. 1091-100.

27. Ashall, L., et al., Pulsatile stimulation determines timing and specificity of NF-kappaBdependent transcription. Science, 2009. 324(5924): p. 242-6.

28. Hoffmann, A., et al., The IkappaB-NF-kappaB signaling module: temporal control and selective gene activation. Science, 2002. 298(5596): p. 1241-5.

29. Jin, F., et al., PU.1 and C/EBP(alpha) synergistically program distinct response to NF-kappaB activation through establishing monocyte specific enhancers. Proc Natl Acad Sci U S A, 2011. 108(13): p. 5290-5.

30. Ramirez-Carrozzi, V.R., et al., $A$ unifying model for the selective regulation of inducible transcription by CpG islands and nucleosome remodeling. Cell, 2009. 138(1): p. 114-28.

31. Ainbinder, E., et al., Mechanism of rapid transcriptional induction of tumor necrosis factor alpha-responsive genes by NF-kappaB. Mol Cell Biol, 2002. 22(18): p. 6354-62.

32. Saccani, S., S. Pantano, and G. Natoli, Two waves of nuclear factor kappaB recruitment to target promoters. J Exp Med, 2001. 193(12): p. 1351-9.

33. Huang, B., et al., Posttranslational modifications of NF-kappaB: another layer of regulation for NF-kappaB signaling pathway. Cell Signal, 2010. 22(9): p. 1282-90.

34. Perkins, N.D., Post-translational modifications regulating the activity and function of the nuclear factor kappa B pathway. Oncogene, 2006. 25(51): p. 6717-30.

35. Sakurai, H., et al., IkappaB kinases phosphorylate NF-kappaB p65 subunit on serine 536 in the transactivation domain. J Biol Chem, 1999. 274(43): p. 30353-6.

36. Zhong, H., R.E. Voll, and S. Ghosh, Phosphorylation of NF-kappa B p65 by PKA stimulates transcriptional activity by promoting a novel bivalent interaction with the coactivator CBP/p300. Mol Cell, 1998. 1(5): p. 661-71.

37. Chen, L.F., et al., NF-kappaB RelA phosphorylation regulates RelA acetylation. Mol Cell Biol, 2005. 25(18): p. 7966-75.

38. Wang, Z., et al., Genome-wide mapping of HATs and HDACs reveals distinct functions in active and inactive genes. Cell, 2009. 138(5): p. 1019-31.

39. Yang, F., et al., IKK beta plays an essential role in the phosphorylation of RelA/p65 on serine 536 induced by lipopolysaccharide. J Immunol, 2003. 170(11): p. 5630-5.

40. Huang, B., et al., Brd4 coactivates transcriptional activation of NF-kappaB via specific binding to acetylated RelA. Mol Cell Biol, 2009. 29(5): p. 1375-87.

41. Amir-Zilberstein, L., et al., Differential regulation of NF-kappaB by elongation factors is determined by core promoter type. Mol Cell Biol, 2007. 27(14): p. 5246-59.

42. Nowak, D.E., et al., RelA Ser276 phosphorylation is required for activation of a subset of NFkappaB-dependent genes by recruiting cyclin-dependent kinase 9/cyclin T1 complexes. Mol Cell Biol, 2008. 28(11): p. 3623-38.

43. Smale, S.T., Hierarchies of NF-kappaB target-gene regulation. Nat Immunol, 2011. 12(8): p. 689-94.

44. Peng, C., et al., Myxoma virus M156 is a specific inhibitor of rabbit PKR but contains a loss-offunction mutation in Australian virus isolates. Proc Natl Acad Sci U S A, 2016. 113(14): p. 3855-60.

45. Elde, N.C. and H.S. Malik, The evolutionary conundrum of pathogen mimicry. Nat Rev Microbiol, 2009. 7(11): p. 787-97.

46. Daugherty, M.D. and H.S. Malik, Rules of engagement: molecular insights from host-virus arms races. Annu Rev Genet, 2012. 46: p. 677-700.

47. McFadden, G., Poxvirus tropism. Nat Rev Microbiol, 2005. 3(3): p. 201-13.

48. Johnston, J.B. and G. McFadden, Poxvirus immunomodulatory strategies: current perspectives. J Virol, 2003. 77(11): p. 6093-100. 
49. Seet, B.T., et al., Poxviruses and immune evasion. Annu Rev Immunol, 2003. 21: p. 377-423.

50. Smith, G.L., et al., Vaccinia virus immune evasion: mechanisms, virulence and immunogenicity. J Gen Virol, 2013. 94(Pt 11): p. 2367-2392.

51. Albarnaz, J.D., A.A. Torres, and G.L. Smith, Modulating Vaccinia Virus Immunomodulators to Improve Immunological Memory. Viruses, 2018. 10(3).

52. Bahar, M.W., et al., How vaccinia virus has evolved to subvert the host immune response. J Struct Biol, 2011. 175(2): p. 127-34.

53. Mansur, D.S., et al., Poxvirus targeting of E3 ligase beta-TrCP by molecular mimicry: a mechanism to inhibit NF-kappaB activation and promote immune evasion and virulence. PLoS Pathog, 2013. 9(2): p. e1003183.

54. Neidel, S., et al., Vaccinia virus protein A49 is an unexpected member of the B-cell Lymphoma (BCl)-2 protein family. J Biol Chem, 2015. 290(10): p. 5991-6002.

55. Neidel, S., et al., NF-kappaB activation is a turn on for vaccinia virus phosphoprotein $A 49$ to turn off NF-kappaB activation. Proc Natl Acad Sci U S A, 2019. 116(12): p. 5699-5704.

56. Sumner, R.P., et al., Vaccinia virus inhibits NF-kappaB-dependent gene expression downstream of $p 65$ translocation. J Virol, 2014. 88(6): p. 3092-102.

57. Perkus, M.E., et al., Deletion of 55 open reading frames from the termini of vaccinia virus. Virology, 1991. 180(1): p. 406-10.

58. Assarsson, E., et al., Kinetic analysis of a complete poxvirus transcriptome reveals an immediate-early class of genes. Proc Natl Acad Sci U S A, 2008. 105(6): p. 2140-5.

59. Yang, Z., et al., Simultaneous high-resolution analysis of vaccinia virus and host cell transcriptomes by deep RNA sequencing. Proc Natl Acad Sci U S A, 2010. 107(25): p. 11513-8.

60. Wente, S.R. and M.P. Rout, The nuclear pore complex and nuclear transport. Cold Spring Harb Perspect Biol, 2010. 2(10): p. a000562.

61. Gubser, C., et al., Poxvirus genomes: a phylogenetic analysis. J Gen Virol, 2004. 85(Pt 1): p. 105-117.

62. Chen, R.A., et al., Inhibition of IkappaB kinase by vaccinia virus virulence factor B14. PLoS Pathog, 2008. 4(2): p. e22.

63. Stuart, J.H., et al., Vaccinia Virus Protein C6 Inhibits Type I IFN Signalling in the Nucleus and Binds to the Transactivation Domain of STAT2. PLoS Pathog, 2016. 12(12): p. e1005955.

64. Torres, A.A., et al., Multiple Bcl-2 family immunomodulators from vaccinia virus regulate MAPK/AP-1 activation. J Gen Virol, 2016. 97(9): p. 2346-2351.

65. Yang, Z., et al., Deciphering poxvirus gene expression by RNA sequencing and ribosome profiling. J Virol, 2015. 89(13): p. 6874-86.

66. Yang, Z., et al., Genome-wide analysis of the 5' and 3' ends of vaccinia virus early mRNAs delineates regulatory sequences of annotated and anomalous transcripts. J Virol, 2011. 85(12): p. 5897-909.

67. Yuen, L. and B. Moss, Oligonucleotide sequence signaling transcriptional termination of vaccinia virus early genes. Proc Natl Acad Sci U S A, 1987. 84(18): p. 6417-21.

68. Unterholzner, L., et al., Vaccinia virus protein $C 6$ is a virulence factor that binds TBK-1 adaptor proteins and inhibits activation of IRF3 and IRF7. PLoS Pathog, 2011. 7(9): p. e1002247.

69. Soday, L., et al., Quantitative Temporal Proteomic Analysis of Vaccinia Virus Infection Reveals Regulation of Histone Deacetylases by an Interferon Antagonist. Cell Rep, 2019. 27(6): p. 1920-1933 e7.

70. Parrish, S. and B. Moss, Characterization of a vaccinia virus mutant with a deletion of the D10R gene encoding a putative negative regulator of gene expression. J Virol, 2006. 80(2): $p$. 553-61.

71. Parrish, S. and B. Moss, Characterization of a second vaccinia virus mRNA-decapping enzyme conserved in poxviruses. J Virol, 2007. 81(23): p. 12973-8. 
72. Ehlers, A., et al., Poxvirus Orthologous Clusters (POCs). Bioinformatics, 2002. 18(11): p. 15445.

73. Kelley, L.A., et al., The Phyre2 web portal for protein modeling, prediction and analysis. Nat Protoc, 2015. 10(6): p. 845-58.

74. Lecoq, L., et al., Structural characterization of interactions between transactivation domain 1 of the p65 subunit of NF-kappaB and transcription regulatory factors. Nucleic Acids Res, 2017. 45(9): p. 5564-5576.

75. Schmitz, M.L., et al., Structural and functional analysis of the NF-kappa B p65 C terminus. An acidic and modular transactivation domain with the potential to adopt an alpha-helical conformation. J Biol Chem, 1994. 269(41): p. 25613-20.

76. Schmitz, M.L. and P.A. Baeuerle, The $p 65$ subunit is responsible for the strong transcription activating potential of NF-kappa B. EMBO J, 1991. 10(12): p. 3805-17.

77. Shi, J. and C.R. Vakoc, The mechanisms behind the therapeutic activity of BET bromodomain inhibition. Mol Cell, 2014. 54(5): p. 728-36.

78. Xing, J., et al., Herpes simplex virus 1-encoded tegument protein VP16 abrogates the production of beta interferon (IFN) by inhibiting NF-kappaB activation and blocking IFN regulatory factor 3 to recruit its coactivator CBP. J Virol, 2013. 87(17): p. 9788-801.

79. Huang, S.M. and D.J. McCance, Down regulation of the interleukin-8 promoter by human papillomavirus type 16 E6 and E7 through effects on CREB binding protein/p300 and P/CAF. J Virol, 2002. 76(17): p. 8710-21.

80. Richards, K.H., et al., The human papillomavirus (HPV) E7 protein antagonises an Imiquimodinduced inflammatory pathway in primary human keratinocytes. Sci Rep, 2015. 5: p. 12922.

81. Spitkovsky, D., et al., The human papillomavirus oncoprotein E7 attenuates NF-kappa B activation by targeting the Ikappa B kinase complex. J Biol Chem, 2002. 277(28): p. 2557682.

82. Vandermark, E.R., et al., Human papillomavirus type 16 E6 and $E 7$ proteins alter NF-kB in cultured cervical epithelial cells and inhibition of NF-kB promotes cell growth and immortalization. Virology, 2012. 425(1): p. 53-60.

83. Pallett, M.A., et al., Vaccinia Virus BBK E3 Ligase Adaptor A55 Targets Importin-Dependent NF-kappaB Activation and Inhibits CD8(+) T-Cell Memory. J Virol, 2019. 93(10).

84. Eaglesham, J.B., et al., Viral and metazoan poxins are cGAMP-specific nucleases that restrict cGAS-STING signalling. Nature, 2019. 566(7743): p. 259-263.

85. Hargreaves, D.C., T. Horng, and R. Medzhitov, Control of inducible gene expression by signaldependent transcriptional elongation. Cell, 2009. 138(1): p. 129-45.

86. Mukherjee, S.P., et al., Analysis of the RelA:CBP/p300 interaction reveals its involvement in NF-kappaB-driven transcription. PLoS Biol, 2013. 11(9): p. e1001647.

87. McCraith, S., et al., Genome-wide analysis of vaccinia virus protein-protein interactions. Proc Natl Acad Sci U S A, 2000. 97(9): p. 4879-84.

88. Bravo Cruz, A.G. and J.L. Shisler, Vaccinia virus $K 1$ ankyrin repeat protein inhibits NF-kappaB activation by preventing RelA acetylation. J Gen Virol, 2016. 97(10): p. 2691-2702.

89. Shisler, J.L. and X.L. Jin, The vaccinia virus $K 1 L$ gene product inhibits host NF-kappaB activation by preventing IkappaBalpha degradation. J Virol, 2004. 78(7): p. 3553-60.

90. Diel, D.G., et al., A nuclear inhibitor of NF-kappaB encoded by a poxvirus. J Virol, 2011. 85(1): p. 264-75.

91. Ning, Z., et al., The $N$ terminus of orf virus-encoded protein 002 inhibits acetylation of NFkappaB p65 by preventing Ser(276) phosphorylation. PLoS One, 2013. 8(3): p. e58854.

92. Zou, Z., et al., Brd4 maintains constitutively active NF-kappaB in cancer cells by binding to acetylated RelA. Oncogene, 2014. 33(18): p. 2395-404.

93. Sun, S.C., et al., NF-kappa B controls expression of inhibitor I kappa B alpha: evidence for an inducible autoregulatory pathway. Science, 1993. 259(5103): p. 1912-5. 
94. Lin, R., et al., Virus-dependent phosphorylation of the IRF-3 transcription factor regulates nuclear translocation, transactivation potential, and proteasome-mediated degradation. Mol Cell Biol, 1998. 18(5): p. 2986-96.

95. Bhattacharya, S., et al., Cooperation of Stat2 and $p 300 / C B P$ in signalling induced by interferon-alpha. Nature, 1996. 383(6598): p. 344-7.

96. Zhang, J.J., et al., Two contact regions between Stat1 and CBP/p300 in interferon gamma signaling. Proc Natl Acad Sci U S A, 1996. 93(26): p. 15092-6.

97. O'Connor, M.J., et al., Characterization of an E1A-CBP interaction defines a novel transcriptional adapter motif (TRAM) in CBP/p300. J Virol, 1999. 73(5): p. 3574-81.

98. Marzio, G., et al., HIV-1 tat transactivator recruits $p 300$ and CREB-binding protein histone acety/transferases to the viral promoter. Proc Natl Acad Sci U S A, 1998. 95(23): p. 13519-24.

99. Nicot, C. and R. Harrod, Distinct p300-responsive mechanisms promote caspase-dependent apoptosis by human T-cell lymphotropic virus type 1 Tax protein. Mol Cell Biol, 2000. 20(22): p. 8580-9.

100. Patel, D., et al., The E6 protein of human papillomavirus type 16 binds to and inhibits coactivation by CBP and p300. EMBO J, 1999. 18(18): p. 5061-72.

101. Eckner, R., et al., Association of $p 300$ and $C B P$ with simian virus 40 large $T$ antigen. Mol Cell Biol, 1996. 16(7): p. 3454-64.

102. Cook, J.L., et al., Role of the E1A Rb-binding domain in repression of the NF-kappa Bdependent defense against tumor necrosis factor-alpha. Proc Natl Acad Sci U S A, 2002. 99(15): p. 9966-71.

103. Gilmore, T.D., Multiple mutations contribute to the oncogenicity of the retroviral oncoprotein v-Rel. Oncogene, 1999. 18(49): p. 6925-37.

104. Lin, J.R., et al., Minimalist ensemble algorithms for genome-wide protein localization prediction. BMC Bioinformatics, 2012. 13: p. 157.

105. Kall, L., A. Krogh, and E.L. Sonnhammer, A combined transmembrane topology and signal peptide prediction method. J Mol Biol, 2004. 338(5): p. 1027-36.

106. Robert, X. and P. Gouet, Deciphering key features in protein structures with the new ENDscript server. Nucleic Acids Res, 2014. 42(Web Server issue): p. W320-4.

107. Gloeckner, C.J., et al., A novel tandem affinity purification strategy for the efficient isolation and characterisation of native protein complexes. Proteomics, 2007. 7(23): p. 4228-34.

108. Maluquer de Motes, C., et al., Vaccinia virus virulence factor $N 1$ can be ubiquitylated on multiple lysine residues. J Gen Virol, 2014. 95(Pt 9): p. 2038-2049.

109. Falkner, F.G. and B. Moss, Transient dominant selection of recombinant vaccinia viruses. J Virol, 1990. 64(6): p. 3108-11.

110. Joklik, W.K., The purification fo four strains of poxvirus. Virology, 1962. 18: p. 9-18.

111. Tscharke, D.C. and G.L. Smith, A model for vaccinia virus pathogenesis and immunity based on intradermal injection of mouse ear pinnae. J Gen Virol, 1999. 80 ( Pt 10): p. 2751-2755.

112. Williamson, J.D., et al., Biological characterization of recombinant vaccinia viruses in mice infected by the respiratory route. J Gen Virol, 1990. 71 ( Pt 11): p. 2761-7. 


\section{FIGURE LEGENDS}
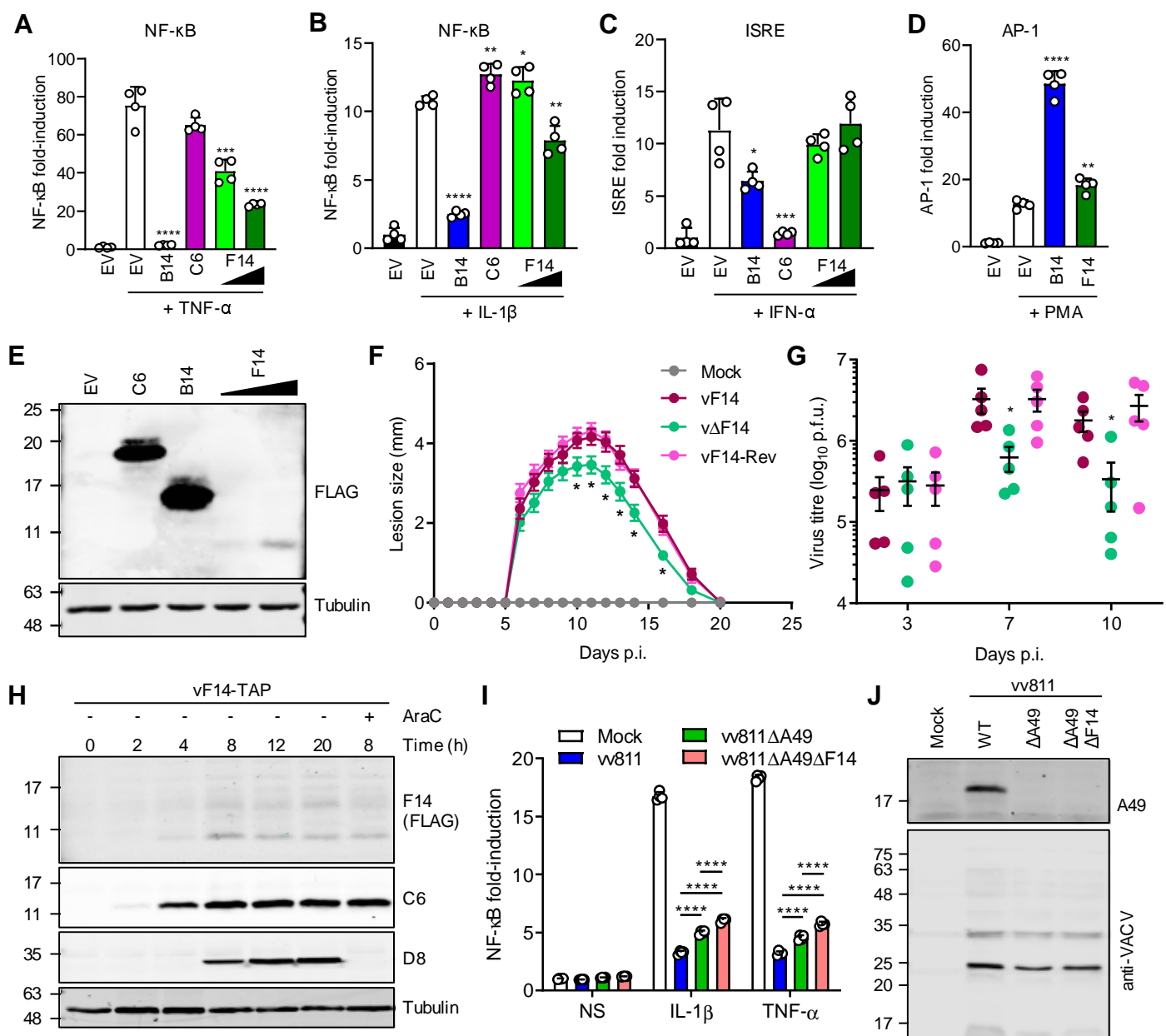

Figure 1: Vaccinia virus protein F14 inhibits NF-кB activation and contributes to virulence. (A-D) HEK 293T cells were transfected with reporter plasmids NF-KB-Fluc (firefly luciferase) (A, B), ISRE-Fluc (C), or AP1-Fluc (D), TK-Renilla, and vectors expressing the indicated VACV proteins fused to a FLAG or tandem affinity purification (TAP) epitope or empty vector (EV). After $16 \mathrm{~h}$, cells were stimulated with TNF- $\alpha, \mathrm{IL}-1 \beta$ or IFN- $\alpha$ (as indicated) for additional $8 \mathrm{~h} \mathrm{(A-C)}$ or $24 \mathrm{~h}$ (D), when luciferase activities were measured. Means + s.d. ( $n=4$ per condition) are shown. (E) Aliquots from whole cell lysates prepared for dual luciferase reporter gene assays were analysed by SDS-PAGE and immunoblotting with antiFLAG and anti-a-tubulin antibodies. (F) C57BL/6 mice were infected intradermally in both ears with $10^{4}$ p.f.u. of the indicated VACV strains and the lesions were measured daily with a calliper. Means \pm s.e.m. $(n=10$ mice $)$ are shown. The asterisk $\left({ }^{*}\right)$ indicates the days on which the lesion size caused by $v \Delta F 14$ was statistically different $(P<0.05)$ from both $v F 14$ and vF14-Rev. (G) Virus titres in the ears of mice infected as in $(\mathbf{F})$ at 3, 7 and $10 \mathrm{~d}$ p.i. were determined by plaque assay. Means \pm s.e.m. $(n=5$ mice) are shown. (H) Immunoblot showing F14 expression during infection. HeLa cells were infected with vF14-TAP at 5 p.f.u./cell for the indicated times and cytosine arabinoside (AraC, $40 \mu \mathrm{g} / \mathrm{ml}$ ) was added where indicated. Immunoblots with antibodies to FLAG (F14), VACV proteins C6 and D8, 
1 and $\alpha$-tubulin. (I) A549 cells transduced with reporter NF-кB-Fluc were infected with VACV

2 vv811 strains at 5 p.f.u./cell. At $6 \mathrm{~h}$ p.i. cells were stimulated with TNF- $\alpha$ or IL-1 $\beta$ for $8 \mathrm{~h}$ and

3 then luciferase activities were measured. Means + s.d. $(n=4$ per condition) are shown. ( $\mathbf{J})$

4 Immunoblots of protein extracts from A549-NF-KB-Fluc cells infected as indicated with

5 antibodies against VACV protein A49, whole VACV virions, and $\alpha$-tubulin. (E, H, J) The

6 positions of molecular mass markers in $\mathrm{kDa}$ are shown on the left of immunoblots. Statistical

7 significance was determined by the Student's $t$-test $\left({ }^{* * *} \mathrm{P}<0.0001,{ }^{* *} \mathrm{P}<0.001,{ }^{* *} \mathrm{P}<0.01\right.$,

$\left.8{ }^{*} \mathrm{P}<0.05\right)$. Data shown in $(\mathbf{A}-\mathbf{D}, \mathbf{I}),(\mathbf{F}, \mathbf{G})$ and $(\mathbf{E}, \mathbf{H}, \mathbf{J})$ are representative of four, two or

9 three separate experiments, respectively. 

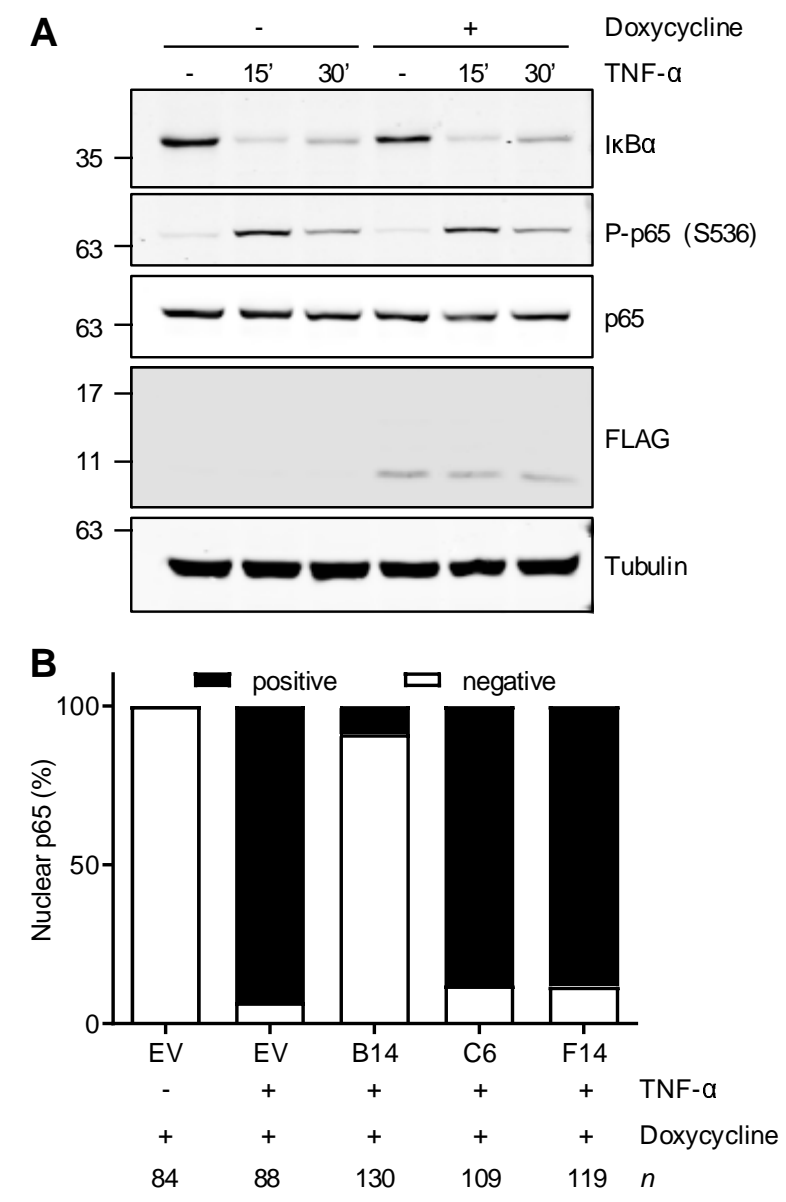

C

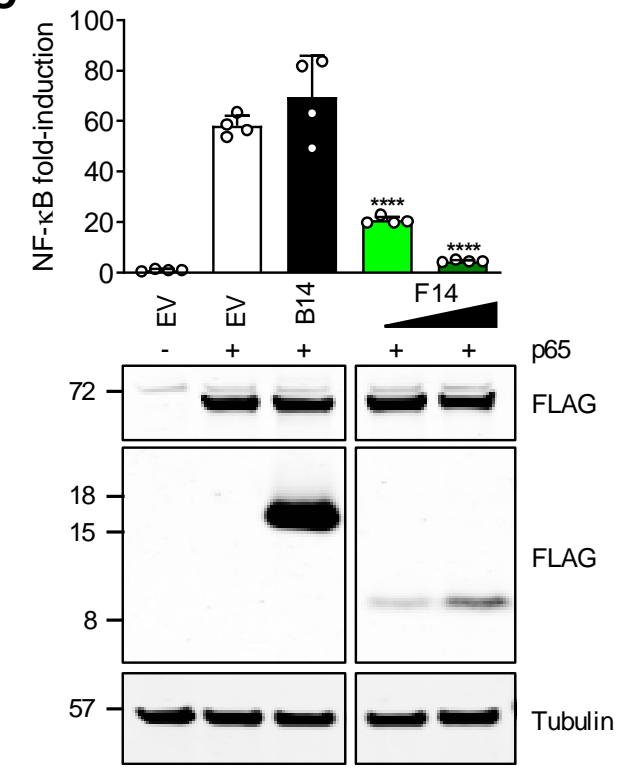

2 Figure 2: F14 inhibits NF-kB at or downstream of p65. (A) Immunoblot showing levels of $3 \quad \mathrm{I} \mathrm{KB} \alpha$, Ser ${ }^{536}$-phosphorylated p65, total p65, F14 (anti-FLAG) and $\alpha$-tubulin in T-REx-293 4 cells inducibly expressing F14 (+ doxycycline) and stimulated with TNF- $\alpha$ as indicated. Data 5 are representative of three independent experiments. (B) T-REx-293 cells inducibly 6 expressing the empty vector (EV) or VACV proteins B14, C6 or F14 were induced with 
1 doxycycline overnight and then stimulated with TNF- $\alpha$ for 15 min. Subcellular localisation of

$2 \mathrm{NF}-\mathrm{kB}$ p65 subunit was assessed by immunofluorescence. The percentages of cells 3 displaying nuclear p65 are shown, with $n$ (number of cells counted from two independent 4 experiments) stated underneath each bar. (C) HEK 293T cells were transfected with reporter 5 plasmids NF-KB-Fluc, TK-Renilla, and vectors expressing human p65-TAP, VACV proteins 6 B14-FLAG and F14-TAP or empty vector (EV). After $24 \mathrm{~h}$, luciferase activities were 7 measured. Top panel: Means + s.d. ( $n=4$ per condition) are shown. Statistical significance 8 was determined by Student's $t$-test $\left.{ }^{* \star \star *} \mathrm{P}<0.0001\right)$. Bottom panel: immunoblots of proteins 9 detected with antibody against the FLAG epitope, and $\alpha$-tubulin. Protein molecular mass 10 markers in $\mathrm{kDa}$ are shown on the left of the blots. 
A

VACV-WR
VACV-COP
MVA
HSPV
MPXV
CPXV
VARV
CMLV
TATV
ECMV
RCNV

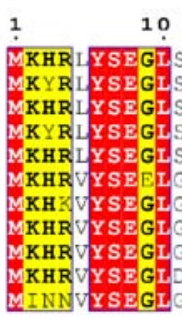

20 STLNSTI 30 TSLNS IGQQ.STMDTDIEIDED SNDLNS I I QQ $Q$ STMD TDIEIDED
SNDLNSI I GQQ. STMD TDIEIDED

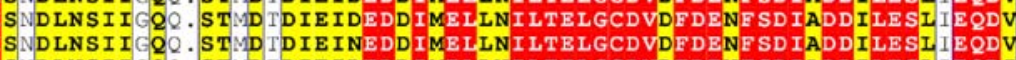
DLNSII QQ S TMD TDIEIDEDDIMELLNI LTEL GCDVDE D ENESD IADDIIESI IEOD I DLNS I I $Q Q$. STMD MDME IDEDE IMELLNI LTB L GDVDF DENE SD IADDI LESI I EQDV TDENSIISQL. ST SDMDIEIDEDNITELLNILTEL GCDVDFDEDF SD I TDDVLESIMEQD

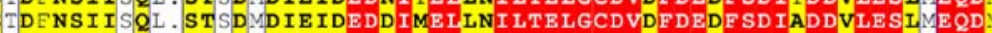

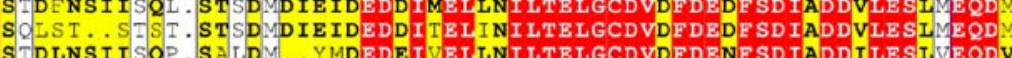

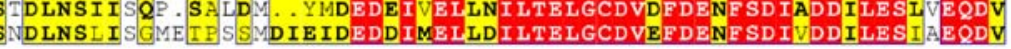

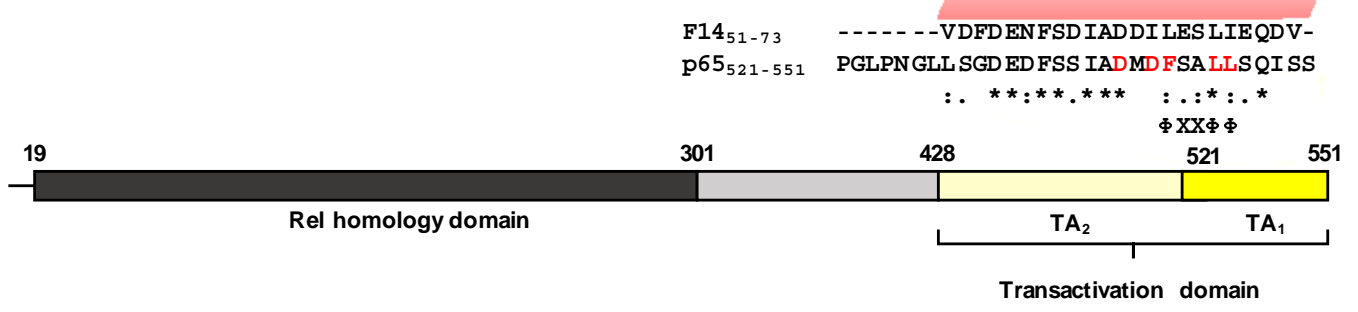

B

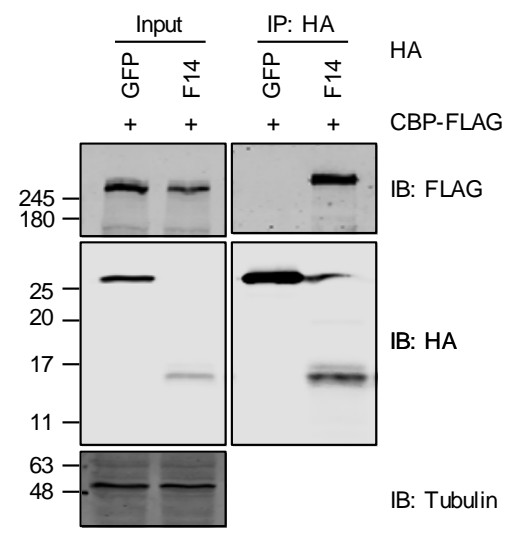

C

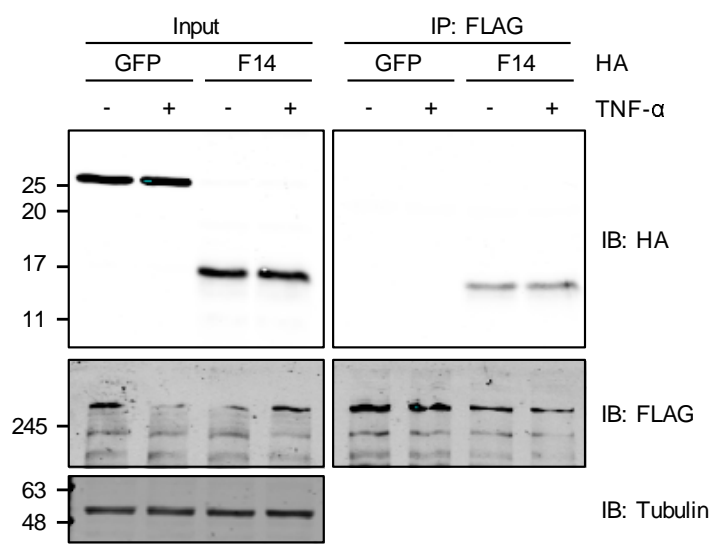

D

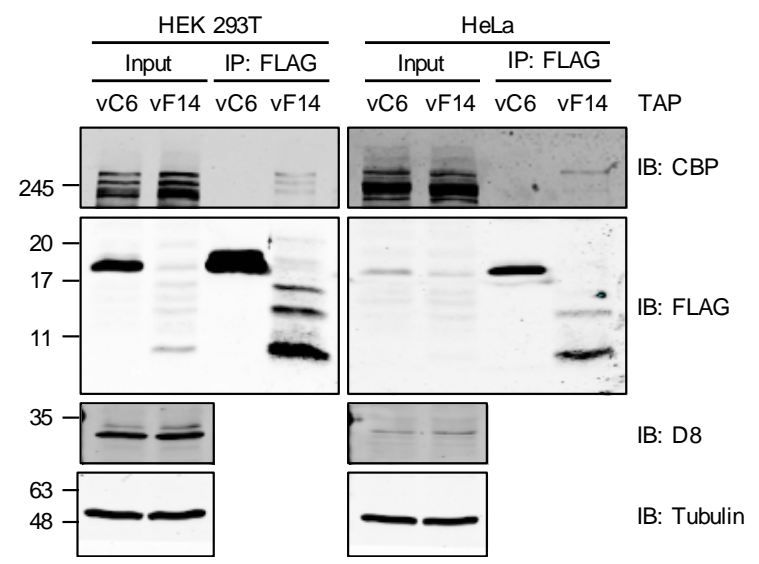

$\mathbf{E}$

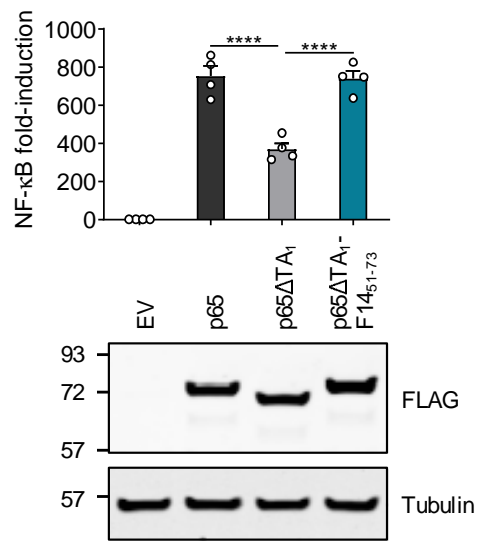

2 Figure 3: F14 binds to CBP and has transactivation activity. (A) Amino acid alignment of 3 F14 orthologues of representative orthopoxviruses: vaccinia virus (VACV) Western Reserve 4 (WR), VACV Copenhagen (Cop), modified vaccinia Ankara (MVA), horsepox virus (HSPV), 5 monkeypox virus (MPXV), cowpox virus (CPXV), variola virus (VARV), camelpox virus 6 (CMLV), taterapox virus (TATV), ectromelia virus (ECMV), and racoonpox virus (RCNV). $7 \quad \operatorname{Red}=$ aa identical in all sequences. Yellow $=$ aa identical in $8 / 11$ sequences. Alignment of 8 the C-termini of F14 and p65 highlighting their sequence similarity including the $\phi \times x \phi \phi$ motif, 9 above a schematic of p65 and its functional domains. (B, C) Lysates from HEK 293T cells 
1 expressing GFP-HA, F14-HA and CBP-FLAG were immunoprecipitated with anti-HA (B) or 2 anti-FLAG (C) and immunoblotted for FLAG- and HA-tagged proteins, and a-tubulin. 3 Immunoblots are representative of three independent experiments. (D) HEK 293T and HeLa 4 cells were infected with VACV strains vC6-TAP or vF14-TAP at 5 p.f.u./cell for $8 \mathrm{~h}$. Cell 5 lysates were immunoprecipitated with anti-FLAG and immunoblotted for CBP, FLAG-tagged $6 \mathrm{C} 6$ and F14, VACV protein D8, and $\alpha$-tubulin. Immunoblots are representative of two 7 independent experiments. (E) HEK 293T cells were transfected with NF-kB-Fluc, TK-Renilla, 8 and vectors expressing human p65-TAP, or p65-TAP mutants or empty vector (EV). Top 9 panel: After $24 \mathrm{~h}$, luciferase activities were measured. Means + s.d. ( $n=4$ per condition) are 10 shown. Statistical significance was determined by the Student's $t$-test $\left({ }^{* * *} P<0.0001\right)$. 11 Bottom panel: immunoblots of p65 (anti-FLAG) and $\alpha$-tubulin. Protein molecular mass 12 markers in $\mathrm{kDa}$ are shown on the left of the blots. 


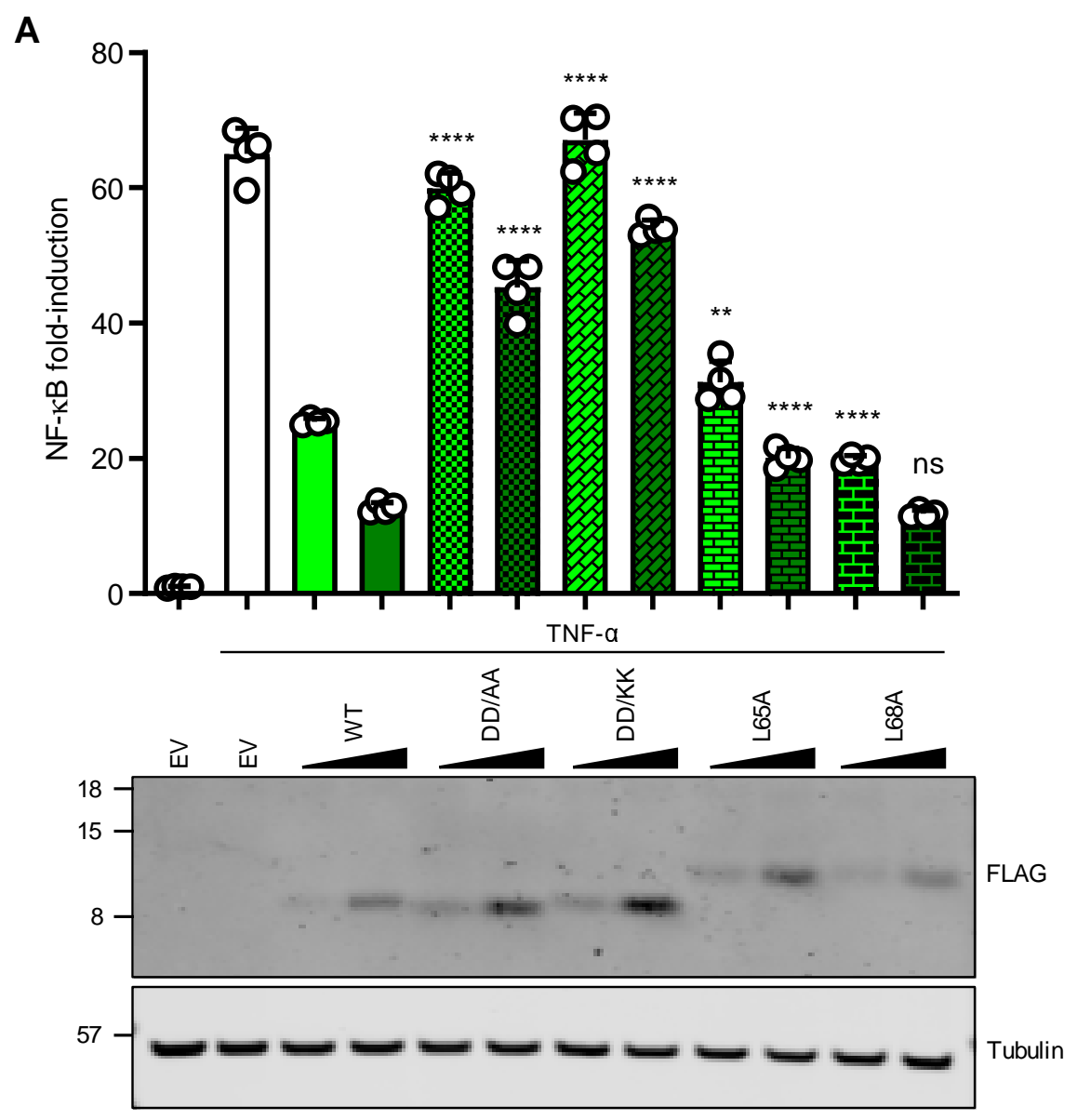

B
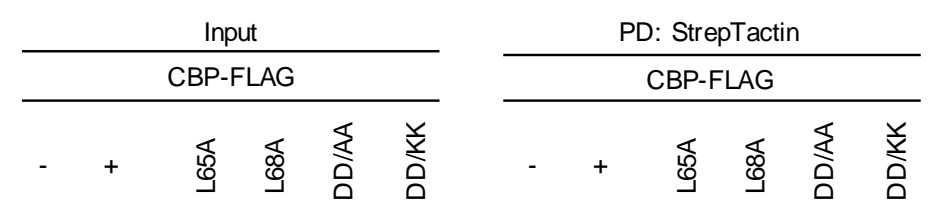

F14-TAP
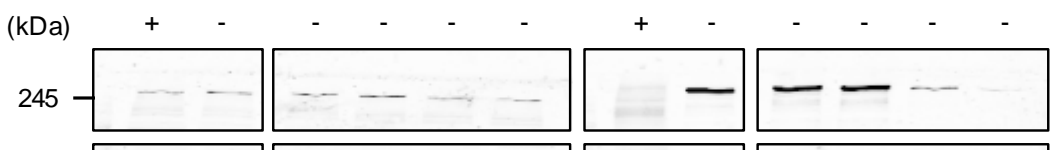

C6-TAP
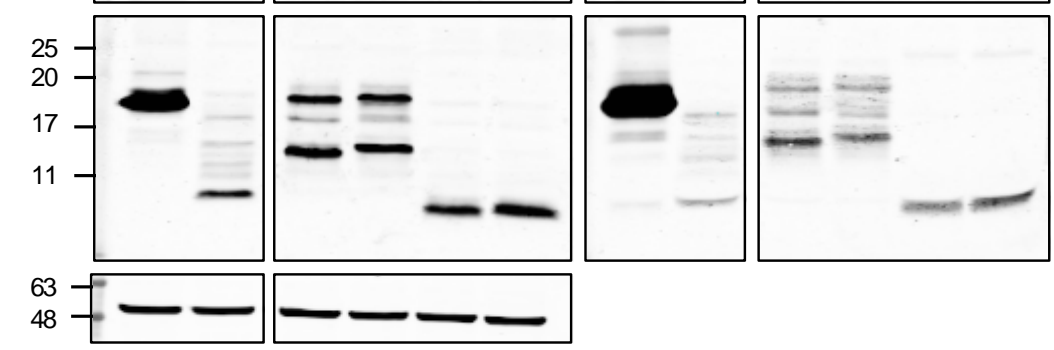

IB: FLAG

IB: FLAG

Figure 4: The dipeptide $\mathrm{Asp}^{62 / 63}$ of $\mathrm{F} 14$ is required for inhibition of NF-kB. (A) HEK

293T cells were transfected with NF-кB-Fluc, TK-Renilla, and increasing concentrations of vectors expressing VACV protein F14 or the indicated mutants, or empty vector (EV). After $16 \mathrm{~h}$, cells were stimulated with TNF- $\alpha$ for $8 \mathrm{~h}$, and then luciferase activities were measured.

6 Top panel: Means + s.d. ( $n=4$ per condition) are shown. Bottom panel: Immunoblots.

7 Aliquots of whole cell lysates prepared for dual luciferase reporter gene assays were blotted

with antibodies against FLAG and a-tubulin. Data are representative of three independent 
1 experiments. Statistical significance was determined by the Student's $t$-test $\left({ }^{\star \star * \star} P<0.0001\right.$, $\left.2{ }^{* * *} P<0.001,{ }^{* *} P<0.01,{ }^{*} P<0.05\right)$. (B) Lysates from HEK $293 T$ cells expressing the 3 indicated proteins were affinity purified with StrepTactin resin and immunoblotted for FLAG 4 and $a$-tubulin. Immunoblots are representative of three independent experiments. DD/AA 5 denotes D62/63A mutant and DD/KK, D62/63K mutant. Protein molecular mass markers in $6 \mathrm{kDa}$ are shown on the left of the blots. 
A
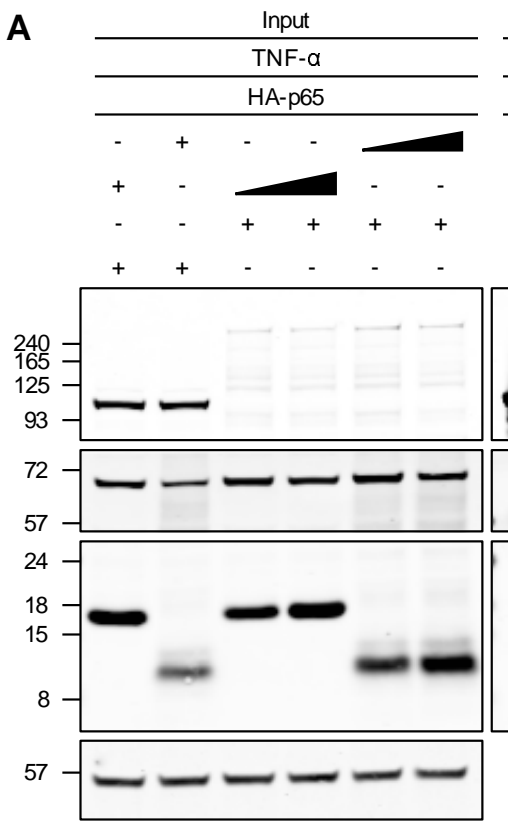

D
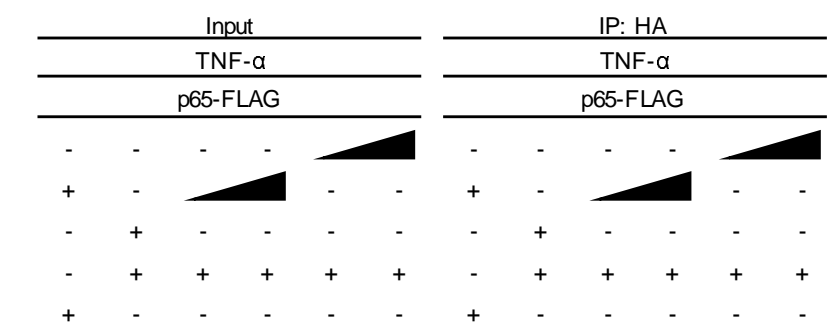

$+\quad-\quad-\quad-\quad-$
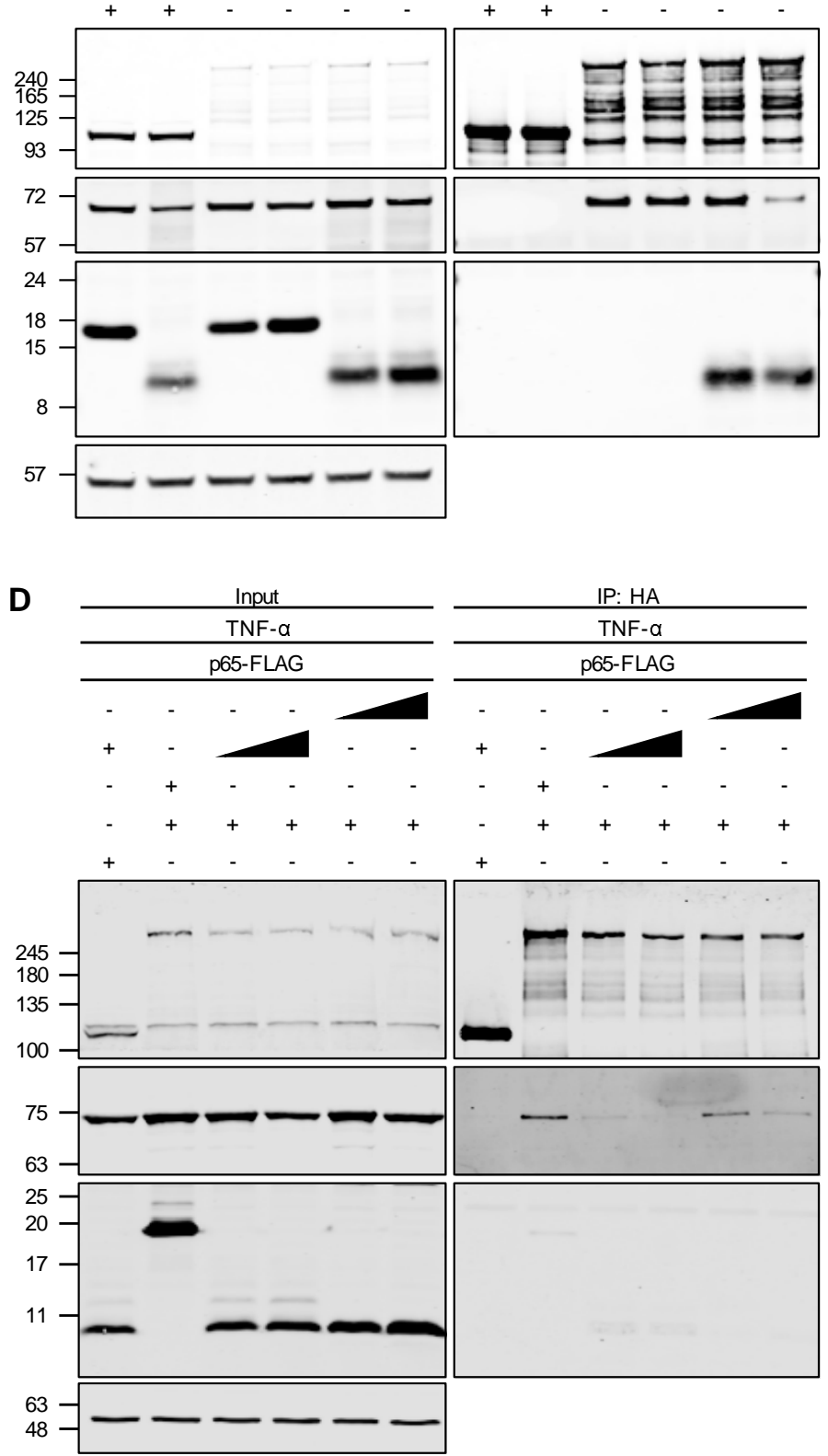

F14-HA

C6-HA

FLAG-CBP

FLAG-RIG-I

IB: $\mathrm{HA}$

IB: Tubulin

IB: FLAG

IB: HA

B: HA
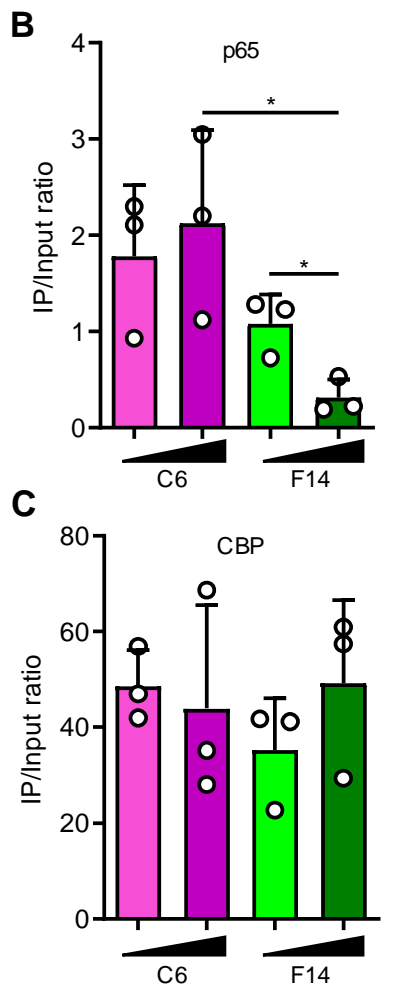

F14-D62/63K-TAP

F14-TAP

C6-TAP

HA-CBP

TAP-RIG-I

IB: HA

IB: FLAG

IB: FLAG

IB: Tubulin

Figure 5: F14 outcompetes NF-KB for binding to CBP. (A, D) Lysates from HEK 293T cells expressing the indicated proteins and stimulated with TNF-a for $15 \mathrm{~min}$ were immunoprecipitated with anti-FLAG (A) or anti-HA (D) and immunoblotted for FLAG, HA and a-tubulin. Immunoblots are representative of three independent experiments. (B, C) Ratio of 6 immunoprecipitate (IP) over input signal intensities from immunoblots as in (A). Means + s.d. $7 \quad(n=3$ independent experiments) are shown. Statistical significance was determined by the 8 Student's $t$-test $\left({ }^{*} P<0.05\right)$. Protein molecular mass markers in $k D a$ are shown on the left of 9 the blots. 
A

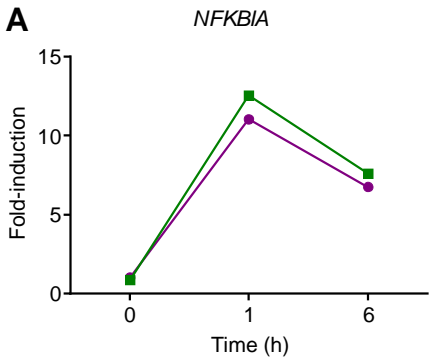

D

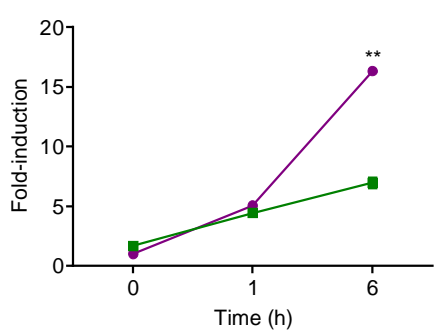

B

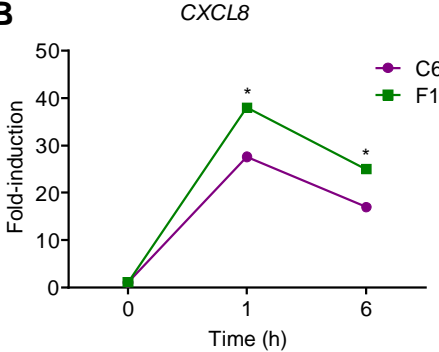

E

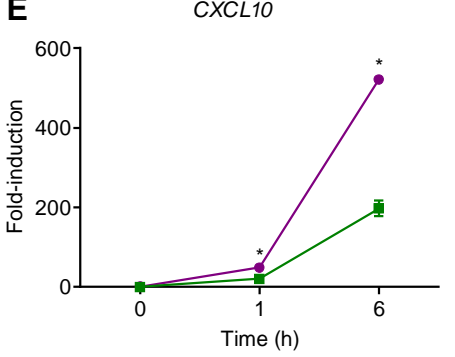

C

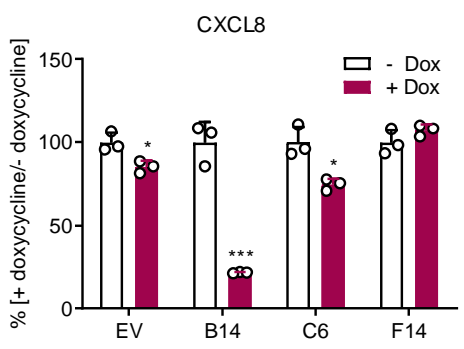

$\mathbf{F}$

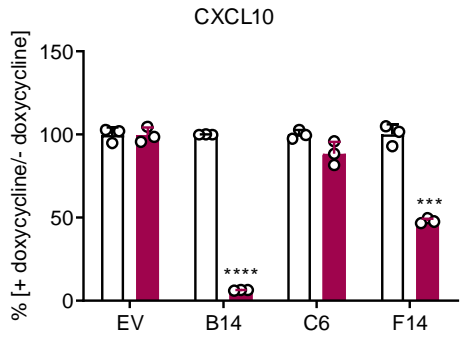

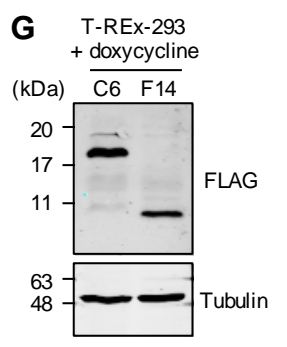

2 Figure 6: F14 suppresses expression of a subset of NF-kB-responsive genes. (A, B, D,

3 E) T-REx-293 cells were induced with doxycycline overnight to express VACV proteins C6 or $4 \mathrm{~F} 14$, and then stimulated with TNF-a for 1 or $6 \mathrm{~h}$. Total RNA was extracted, and mRNA for 5 indicated NF-kB-responsive genes was analysed by RT-qPCR. Means \pm s.d. $(n=2$ per 6 condition) are shown. (C, F) T-REx-293 cells inducibly expressing the empty vector (EV) or 7 VACV proteins B14, C6 or F14 were induced with doxycycline overnight and then stimulated 8 with TNF-a for $16 \mathrm{~h}$. The concentration of CXCL8 and CXCL10 in the culture supernatants 9 was measured by ELISA. Means + s.d. ( $n=3$ per condition) of the percent of secretion in presence of doxycycline (+dox) in comparison to secretion in the absence of doxycycline (dox, equals $100 \%$ ) are shown. Statistical significance was determined by the Student's $t$-test $\left({ }^{* * *} \mathrm{P}<0.0001,{ }^{* *} \mathrm{P}<0.001,{ }^{* *} \mathrm{P}<0.01,{ }^{*} \mathrm{P}<0.05\right)$. (G, H) Protein extracts from T-REx-293 cell lines were immunoblotted with antibodies against the FLAG or $\alpha$-tubulin. Protein molecular masses in $\mathrm{kDa}$ are shown on the left of the blots. 

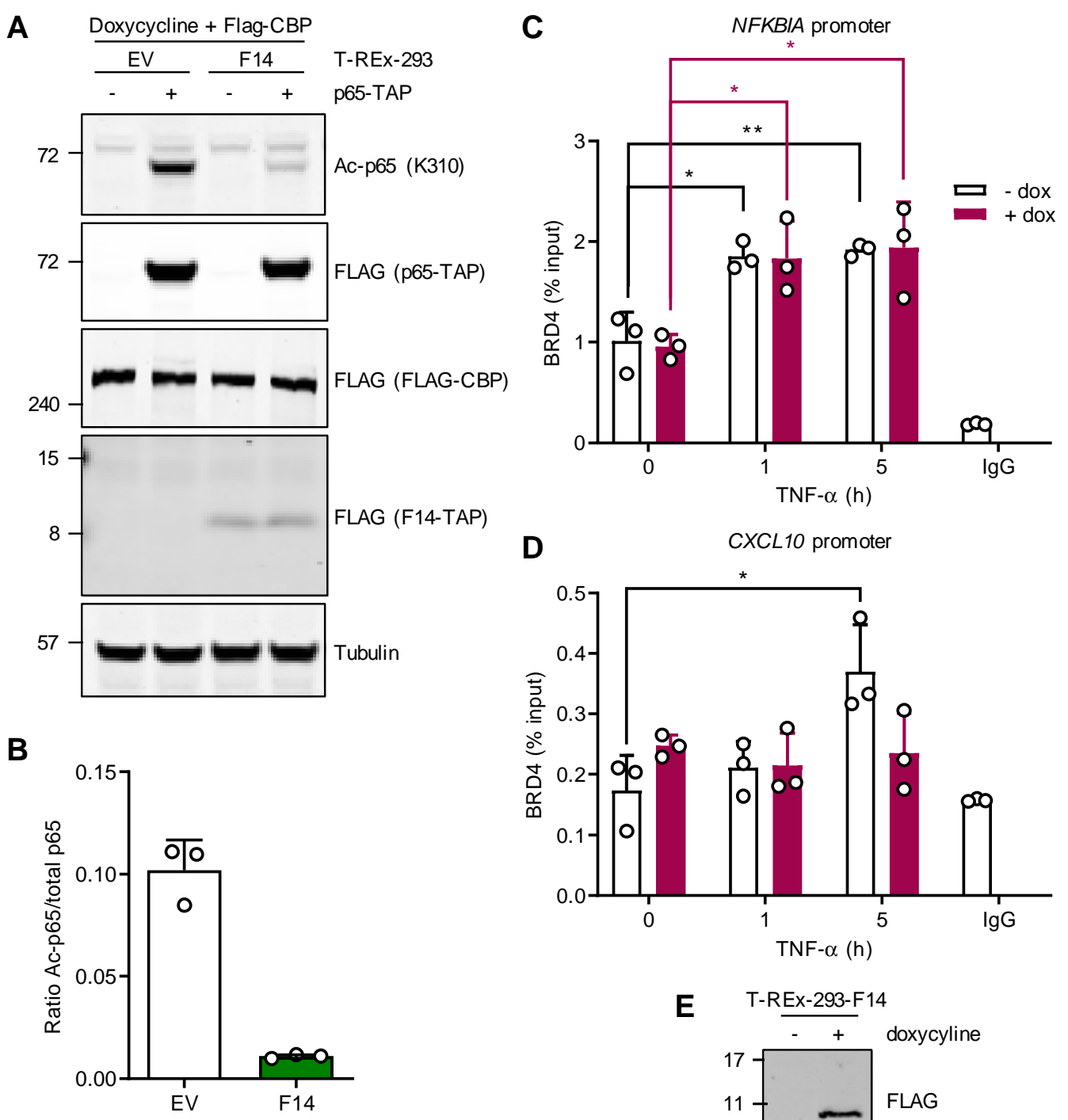

2 Figure 7: F14 antagonises p65 acetylation and BRD4 recruitment to CXCL10 promoter.

3 (A) Immunoblot analysis of p65 Lys ${ }^{310}$ acetylation. T-REx-293 cells stably transfected with 4 empty vector (EV) or a plasmid inducibly expressing F14 were induced with doxycycline overnight. Cells were then transfected with plasmids for expression of p65-TAP and FLAGCBP overnight and lysates were immunoblotted with anti-FLAG and anti- $\alpha$-tubulin. Blots are representative of two independent experiments carried out with three biological replicates each. (B) Ratio of acetylated (Ac) p65 over total ectopic p65 signal intensities from immunoblots in (A). Means + s.d. ( $n=3$ per condition) are shown. (C, D) T-REx-293 cells stably expressing inducible F14 were induced with doxycycline overnight before stimulation with TNF-a for 1 or $5 \mathrm{~h}$. Chromatin immunoprecipitation (ChIP) was carried out with antiBRD4 antibody or control lgG, and immunoprecipitated DNA was analysed by qPCR for the promoters of NFKBIA (C) and CXCL10 (D) genes. Means + s.d. ( $n=3$ per condition) are shown. Statistical significance was determined by the Student's $t$-test $\left({ }^{* *} P<0.01,{ }^{*} P<0.05\right)$. (E) Immunoblots of protein extracts from T-REx-293 cells harvested in parallel to ChIP to detect the expression of F14-FLAG and $\alpha$-tubulin. Protein molecular mass markers in kDa are shown on the left of the blots. 
A

$>H S V-1 \_V P 16_{413-490}$

APP TDV SLG DE LHL DGEDV AMAHAD AL DDF DLDML GDGDSP GPG FT PHD SAP YGALDMAD FE FEQ MFT DA LGI DEYGG
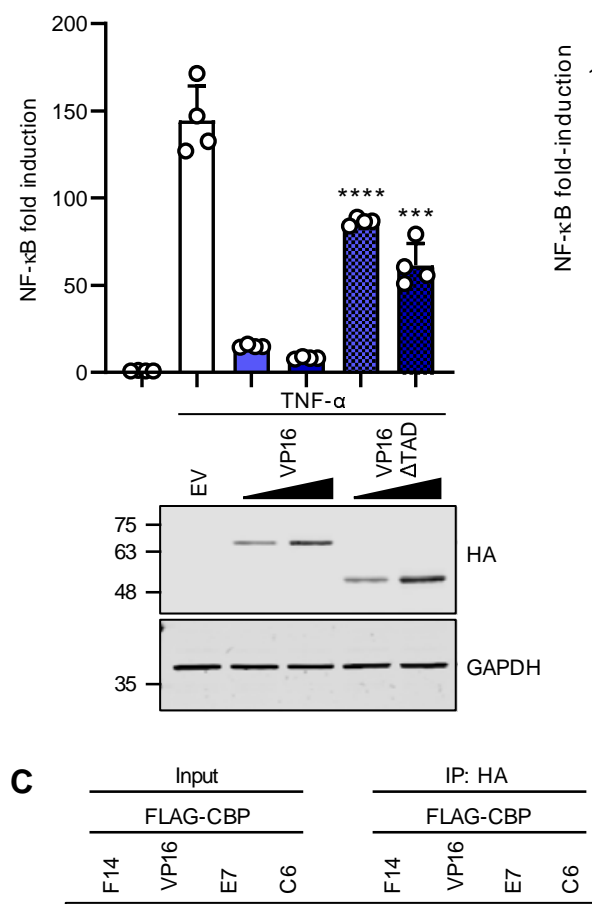
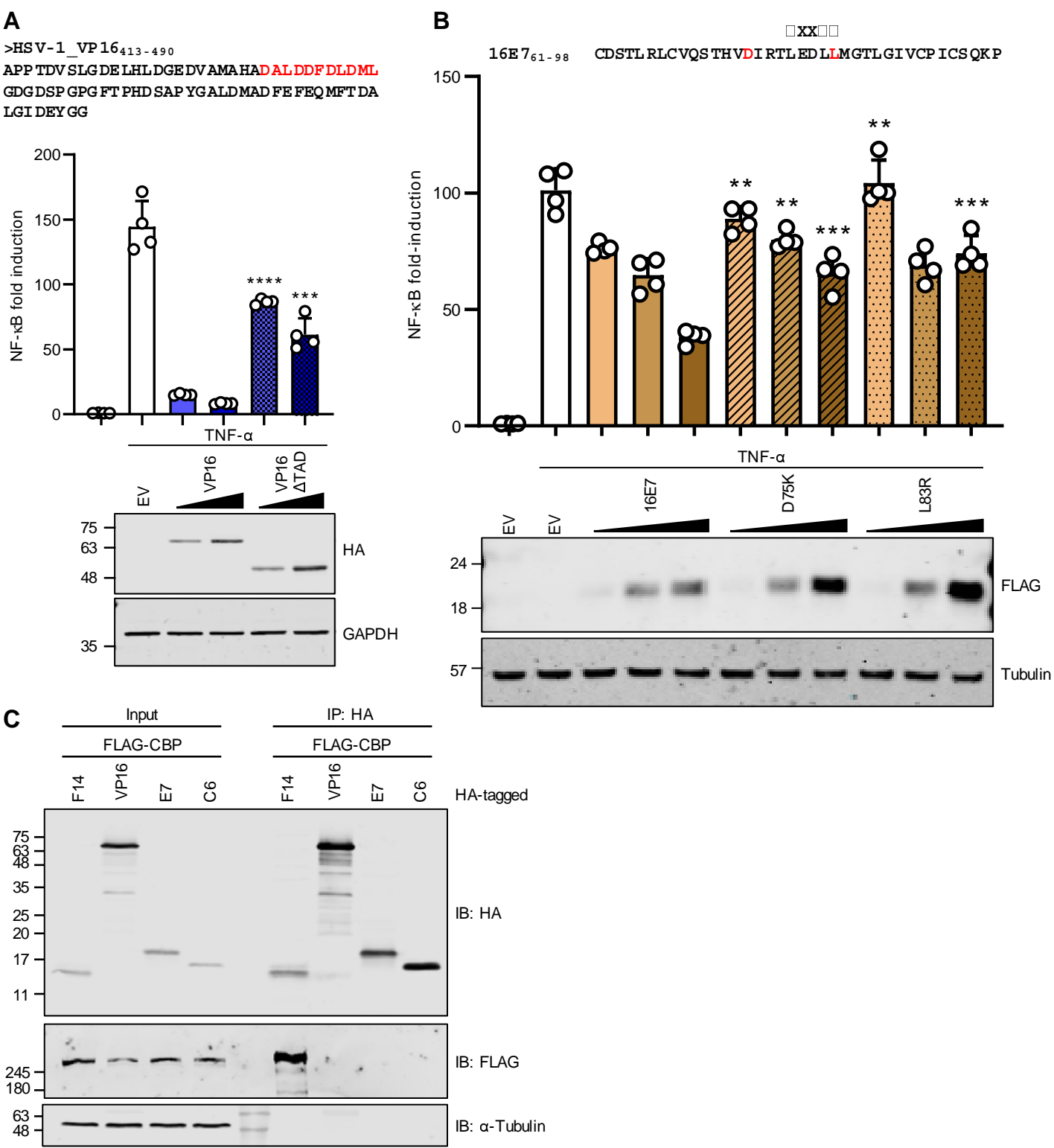

Figure 8: F14 is a unique viral inhibitor of NF-kB. (A) Top: Amino acid sequence of the TAD of HSV-1 VP16 with the acidic activation domain similar to p65 highlighted in red. Middle: HEK 293T cells were transfected with NF-KB-Fluc, TK-Renilla and increasing concentrations of vectors expressing VP16 or a mutant lacking the TAD domain, or empty vector (EV). After $16 \mathrm{~h}$, cells were stimulated with TNF- $\alpha$ for $8 \mathrm{~h}$ and then luciferase activities were measured. Means + s.d. ( $n=4$ per condition) are shown. Bottom: Aliquots from whole cell lysates prepared for dual luciferase reporter gene assays were immunoblotted with antibodies against HA and GAPDH. (B) Top: Amino acid residues 61-98 from HPV16 protein E7 encompassing a $\phi \times x \phi \phi$ motif containing and preceded by negatively charged residues. Highlighted are two residues mutated to disrupt this motif. Middle: Wildtype 16E7 and its two mutants (D75K and L83R) were tested in the NF- $\mathrm{KB}$ luciferase reporter gene assay as described in (A). Bottom: Immunoblots with antibodies against FLAG and $\alpha$-tubulin. Statistical significance was determined by the Student's $t$-test $\left({ }^{* * *} P<0.0001,{ }^{* \star *} P<0.001\right.$, ${ }^{* * P}<0.01$ ). (C) Lysates from HEK 293T cells expressing VACV F14, HSV-1 VP16, HPV E7 and VACV C6 (all HA-tagged) were immunoprecipitated with anti-HA and immunoblotted for 
bioRxiv preprint doi: https://doi.org/10.1101/2020.10.23.353060; this version posted October 23, 2020. The copyright holder for this preprint (which was not certified by peer review) is the author/funder, who has granted bioRxiv a license to display the preprint in perpetuity. It is made available under aCC-BY 4.0 International license.

1 FLAG, HA and a-tubulin. Immunoblots are representative of two independent experiments.

2 Protein molecular masses in $\mathrm{kDa}$ are shown on the left of the blots.

3 


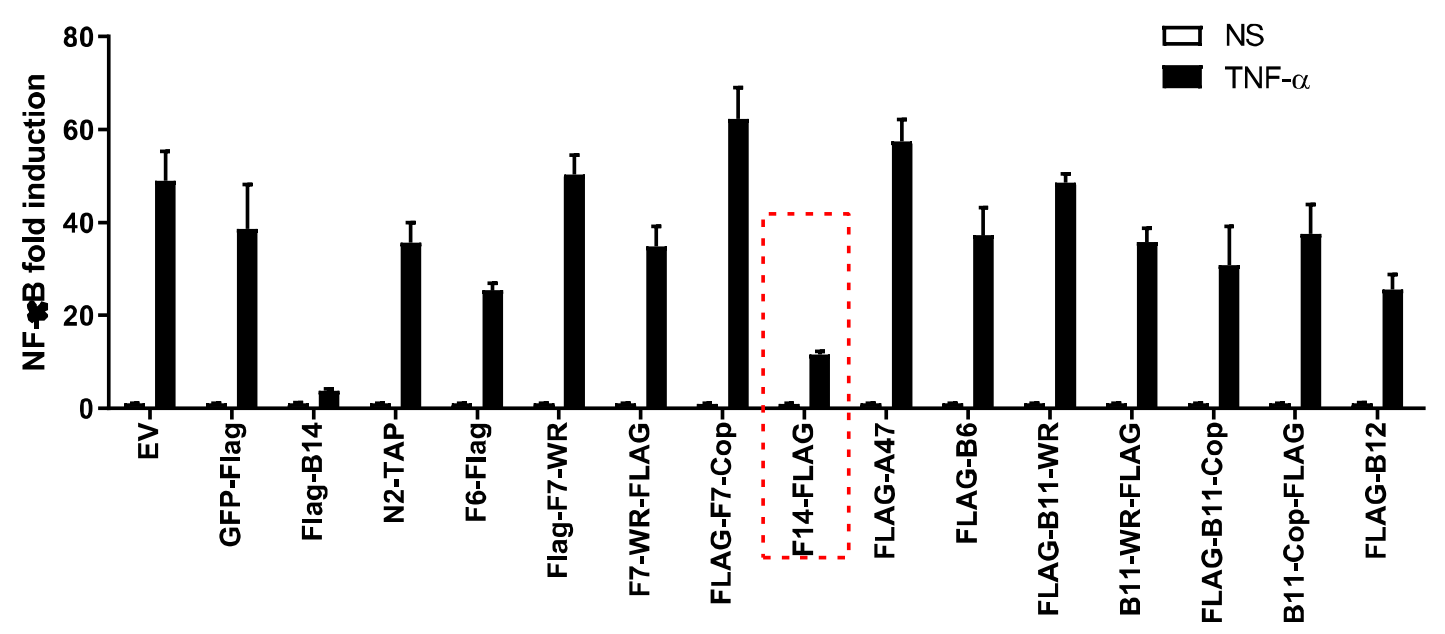

4 Figure S1, related to Figure 1: Screen of VACV strain WR ORFs for NF-kB inhibitory 5 activity. HEK 293T cells were transfected with NF-kB-Fluc, TK-Renilla, and vectors expressing human codon-optimised and FLAG-tagged versions of the indicated VACV proteins or empty vector (EV). After $16 \mathrm{~h}$, cells were stimulated with TNF- $\alpha$ or mock stimulated (NS) for $8 \mathrm{~h}$, and then luciferase activities were measured. Means + s.d. $(n=4$ 9 per condition) are shown. 


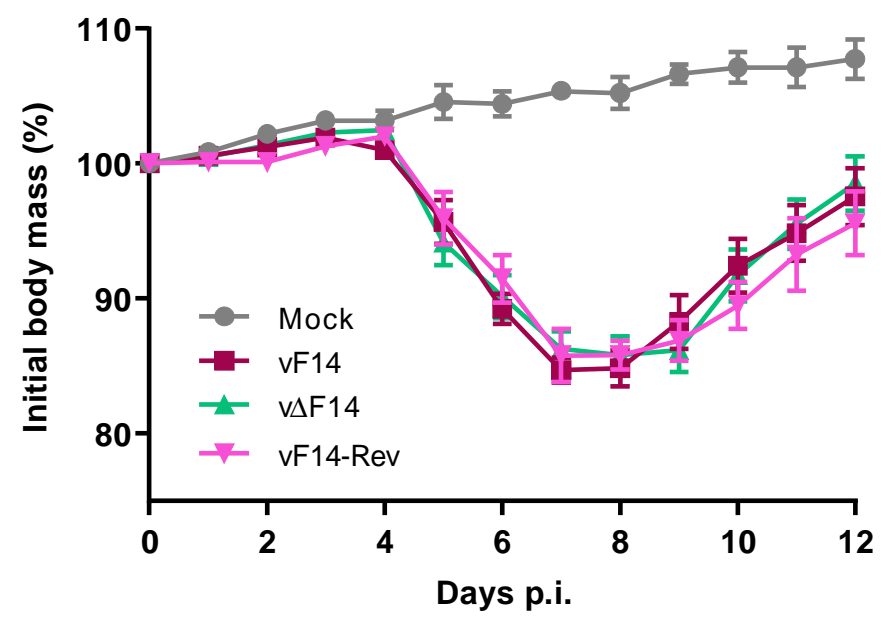

2 Figure S2, related to Figure 1: Virulence of VACV mutant lacking F14 in the intranasal 3 mouse model of infection. BALB/c mice were infected intranasally with $5 \times 10^{3}$ p.f.u. of the 4 indicated VACV strains and their body mass was measured daily. Body mass is expressed 5 as the percentage \pm s.e.m. of the mean of the same group of mice on day 0 ( $n=10$ mice). 


\section{A}

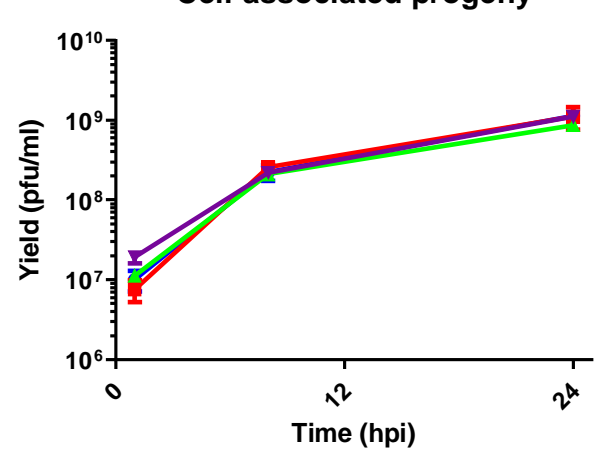

vF14

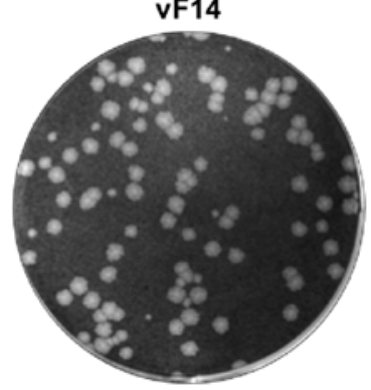

B

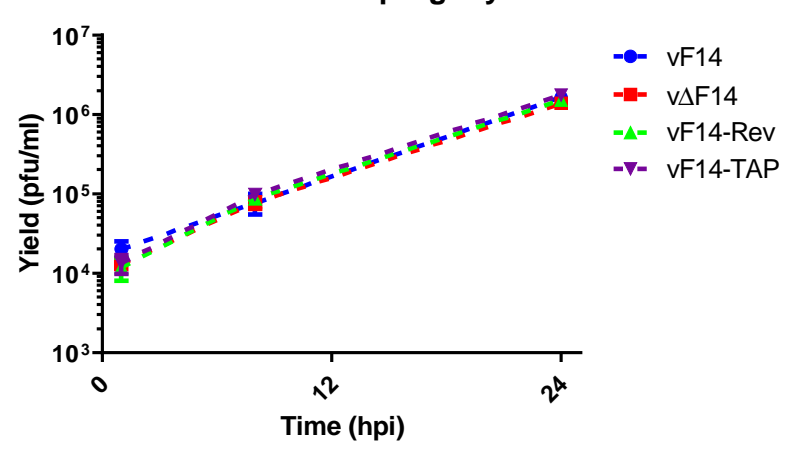

2 Figure S3, related to Figure 1: Replication and spread of VACV mutant lacking F14 in 3 cell culture. (A, B) HeLa cells were infected with the indicated VACV strains at 5 p.f.u./cell. 4 At 1,12 and $24 \mathrm{~h}$ p.i., infectious virus titres associated with the cells $(\mathbf{A})$ and in the 5 supernatants $(\mathbf{B})$ was determined by plaque assay. Means \pm s.d. ( $n=4$ per condition) are 6 shown. (C) Plaque formation by the indicated VACV strains on BS-C- 1 cells. 


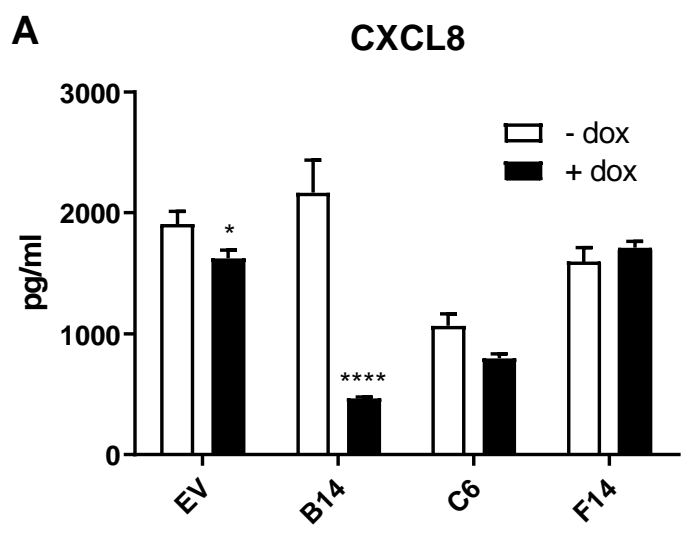

B

CXCL10

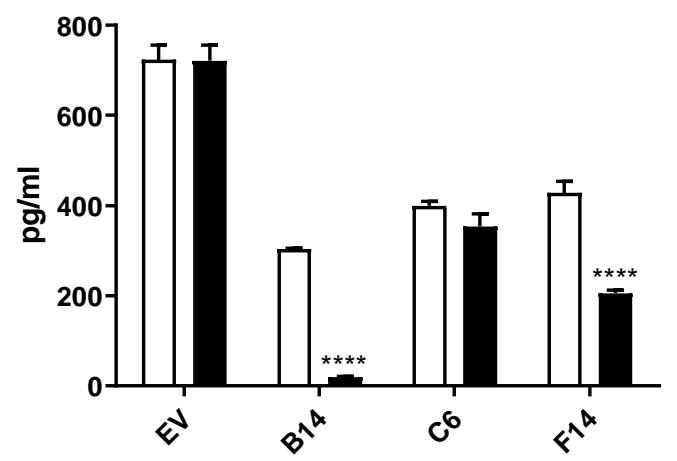

2 Figure S4, related to Figure 6: F14 suppresses expression CXCL10, but not CXCL8, 3 after stimulation with TNF-a. This shows data normalised for presentation in Figure 6C, F. $4 \quad$ T-REx-293 cells stably transfected with empty vector (EV) or plasmids inducibly expressing 5 VACV proteins B14, C6 or F14 (all TAP-tagged) were induced with doxycycline (+dox) or 6 mock-induced (-dox) overnight and then stimulated with TNF-a for $16 \mathrm{~h}$. The concentration 7 of CXCL8 and CXCL10 in the supernatants from these cells was measured by ELISA. 8 Means + s.d. $(n=3$ per condition) are shown. Statistical significance was determined by the 9 Student's $t$-test $\left({ }^{* * *} \mathrm{P}<0.0001,{ }^{*} \mathrm{P}<0.05\right)$.

Table S1: Oligonucleotide primers used in this study. Primers are listed 5' to 3'. Restriction sites used are highlighted in red and indicated in parentheses following oligonucleotide sequence. If present, sequences coding the tag epitopes are highlighted in bold, whilst the Kozak sequence are shown in italics. Plasmids marked with an asterisk $\left(^{*}\right)$ were constructed by site-directed mutagenesis, with the mutated codons underlined.

Table S2: Antibodies used in this study. 